\title{
Effects of mid-level moisture and environmental flow on the development of afternoon thunderstorms in Taipei
}

\author{
Satoki Tsujino ${ }^{1,4}$, Hung-Chi Kuo ${ }^{1}$, Hungjui $\mathrm{Yu}^{1}$, Buo-Fu Chen ${ }^{2, *}$, and Kazuhisa Tsuboki ${ }^{3}$ \\ ${ }^{1}$ Department of Atmospheric Sciences, National Taiwan University, Taipei City, Taiwan \\ ${ }^{2}$ Center for Weather Climate and Disaster Research, National Taiwan University, Taipei City, Taiwan \\ ${ }^{3}$ Institute for Space-Earth Environmental Research, Nagoya University, Nagoya, Japan \\ ${ }^{4}$ Meteorological Research Institute, Tsukuba, Japan
}

\section{Article history:}

Received 13 June 2021

Revised 29 September 2021

Accepted 17 November 2021

\section{Keywords:}

Meso-convective system, Sea-breeze circulation, Convective precipitation, Nonhydrostatic model

Citation:

Tsujino, S., H.-C. Kuo, H. Yu, B.-F. Chen, and K. Tsuboki, 2021: Effects of mid-level moisture and environmental flow on the development of afternoon thunderstorms in Taipei. Terr. Atmos. Ocean. Sci., 32, 497-518, doi: 10.3319/TAO.2021.11.17.01

\begin{abstract}
Afternoon thunderstorms (TSs) over the Taipei metropolitan area often cause meteorological disasters. Further understanding of essential factors for TS organization is important for improving prediction accuracy. This study conducts numerical simulations in two real situations with different environmental profiles: a heavy rainfall (TS) case and a no rainfall (NoTS) case. The TS simulation reasonably captures the afternoon rainfall in the Taipei basin. The thermal structure and sea breeze evolution in the simulations are verified by the observation from a field campaign. In both cases, the sea breeze develops in the afternoon. Weak environmental flow and high humidity are observed in the TS case. In contrast, a thick and dry layer with southeasterly wind above 2-km height is presented in the NoTS case. Four idealized experiments are then performed with the initial conditions based on the actual TS/ NoTS soundings and with/without the southeasterly environmental flows. Despite the different thermal profiles, the two simulations without the southeasterly flows exhibit qualitatively similar rainfall distribution and the evolution of the sea breeze to that of the real TS simulation. However, with the southeasterly environmental flows, the simulation with the NoTS sounding exhibits considerably less convection and rainfall. Therefore, not only moisture profiles but also environmental wind profiles are critical to the TS organization. Novelly, this study further shows that the environmental flow contributes to the suppression of afternoon TSs through keeping entrainment due to the continuous supply of the dry airmass.
\end{abstract}

\section{INTRODUCTION}

During the Mei-yu and summer seasons, afternoon deep convective clouds often form over the Taipei basin without significant synoptic disturbances around Taiwan (e.g., Johnson and Bresch 1991; Lin et al. 2011a, b). The convective clouds organize and develop under favorable conditions. The well-developed clouds can cause meteorological disasters, such as heavy rainfall, lightning, and floods in the metropolitan area. A further understanding of essential factors for thunderstorm (TS) development over the Taipei basin is essential for a more accurate prediction with numerical models.

Johnson and Bresch (1991) examined the afternoon

\footnotetext{
* Corresponding author

E-mail:bfchen@ntu.edu.tw
}

TSs and rainfalls with observations during the Taiwan Area Mesoscale Experiment (TAMEX) field campaign. They examined the evolution of horizontal winds in atmospheric soundings and surface observatories and proposed that the sea breeze circulation can induce the afternoon TSs. After that, many other studies have proposed possible factors for the organization of the afternoon TSs over the Taipei basin. The proposed factors can be roughly divided into (1) local factors such as topography (e.g., Chen et al. 1991, 2010; Kuo and $\mathrm{Wu} 2019$ ), land surface temperature and moisture (e.g., Lin et al. 2011b), and urbanization (e.g., Lin et al. 2011a) and (2) large-scale factors such as low-level (e.g., Kuo and Wu 2019) and middle-level (e.g., Chen et al. 2010) wind profiles and middle-level moisture profile (e.g., Lin et al. 2011b). In addition, cloud dynamics and microphysics such 
as convective-cell merging are also crucial for the organization (e.g., Jou et al. 2016; Miao and Yang 2020).

The proposed local factors can influence sea-breeze circulation and horizontal convergence over the Taipei basin (i.e., formation of the deep TS clouds). The large-scale factors can influence the organization and development of the formed TS clouds. Although a straightforward way to examine the factors is to compare the factors in an afternoon rainfall case with those in no rainfall case (e.g., Lin et al. 2011b; Chen et al. 2014), it is too difficult to get the information on the wind and thermal structure by the radars in the no rainfall case.

Previous studies of rainfall over Taipei have shown that, under weak-synoptic conditions, about $75 \%$ of rainfall in the basin is produced by afternoon TSs triggered by sea breeze interactions with the mountains to the south of the basin (Chen et al. 2007; Lin et al. 2011b). The subsequent interaction between the sea breeze and the outflows from convection near the mountain range may eventually trigger convection initiation and associated flash floods over the ba$\sin$. Without the influence of weather systems such as TCs or fronts, the mechanisms for these locally triggered TS events involve multiscale interactions of dynamic and thermodynamic processes, which possess a shorter lead time for forecasting and a much greater challenge in hydrometeorology.

From June to August 2018, a field campaign aiming to understand the afternoon TSs was conducted in the Taipei basin: (Taipei Summer Storm Experiment; TASSE). Highly frequent atmospheric soundings at multiple locations were operated in the TASSE, capturing detailed boundary layer (BL) structure evolution. The project also conducted additional upper-air atmospheric radiosonde at an operational observatory in the Central Weather Bureau (CWB), corresponding to dynamic and thermodynamic structure in the environment. Data observed in the project may provide new information on the BL structure associated with sea-breeze circulation during the daytime. However, the number of the data is still limited for statistical studies. Thus, we focus on one case with clear afternoon TSs over the Taipei basin and incorporate the numerical simulation to understand the TS development further.

The present study is motivated to clarify essential factors for afternoon TS organization. In particular, we focus on the roles of the BL evolution and dynamic and thermodynamic structure in the environment, which are well captured in detail during the TASSE. Specifically, realistic numerical simulations with a horizontal grid spacing of a sub-km scale are performed for a TS case and a no-TS case to examine the essential factors for TS organization. Furthermore, the high-frequent TASSE observations are used to verify the simulations. Possible essential factors for TS development are discussed by comparing the environmental dynamical and thermodynamical structures between the TS and no-TS cases. Moreover, additional sensitivity experiments with more idealized settings are performed to isolate and directly examine the effects of the proposed essential factors. Note that the target case was not an extreme precipitation case (e.g., > $100 \mathrm{~mm} \mathrm{~h}^{-1}$ ), as we focus on the factors applicable to TSs with a wider range of precipitation rather than only extreme cases.

This paper is organized as follows. Section 2 provides an overview of target cases, and section 3 describes the methodology and data. In section 4 , the results are presented regarding the two realistic numerical simulations for the TS and no-TS cases. Section 5 further conducts four idealized numerical experiments to explore the roles of the vertical thermal profile and environmental background flows. Finally, section 6 provides conclusive remarks.

\section{OVERVIEW OF TARGET CASES}

The TASSE was conducted under the support of the Ministry of Science and Technology (MOST), Taiwan. One major component in TASSE was an upper-air radiosonde observational network over the Taipei basin, which comprises the CWB operational site (Banqiao), the site inside the basin and close to the mountain (NTU, Xindian), and the sites located at the estuaries (Chidu, Shezi, TNUA). The target in the present study is an afternoon rainfall event that occurred in the Taipei basin on 30 June 2018 (TS case) during the campaign. For the TS case, Taiwan was located on the southwestern edge of the subtropical high. The environmental situation had weak synoptic disturbances despite a tropical storm having a considerable distance from Taiwan (Fig. 1a). There was a local peak of the daily accumulated rainfall $(\sim 30 \mathrm{~mm})$ around the Taipei basin (Fig. 1b). The rain gauge in Taipei (CWB-ID: 466920) observed a maximum rainfall rate of $31.4 \mathrm{~mm} \mathrm{~h}^{-1}$ around $1500 \mathrm{LST}$. The evolution of the TSs was captured by the operational radar network in the CWB. In the morning, high radar reflectivity corresponding to heavy precipitation clouds was not observed in the Taipei basin (Figs. 2a, b). Then, some clouds formed around the Taipei basin at 1200 LST on 30 June 2018 (Fig. 2c). The clouds rapidly developed over the Taipei basin in the early afternoon (Figs. $2 d-f$ ). Finally, the TS clouds gradually decayed later in the afternoon (Figs. $2 g$ - i).

On the other hand, the no rainfall (NoTS) case on 26 June 2018 was chosen to compare the essential factors with the TS case (Fig. 1d). Like the TS case, Taiwan was located on the southwestern side of the subtropical high (Fig. 1c). Since there are no significant synoptic disturbances for both cases, it is expected that clear diurnal circulations can occur around the Taipei basin.

\section{METHODOLOGY AND DATA}

\subsection{Model Description}

The numerical experiments were conducted using the Cloud Resolving Storm Simulator (CReSS 3.4.2), a threedimensional, compressible non-hydrostatic model (Tsuboki 

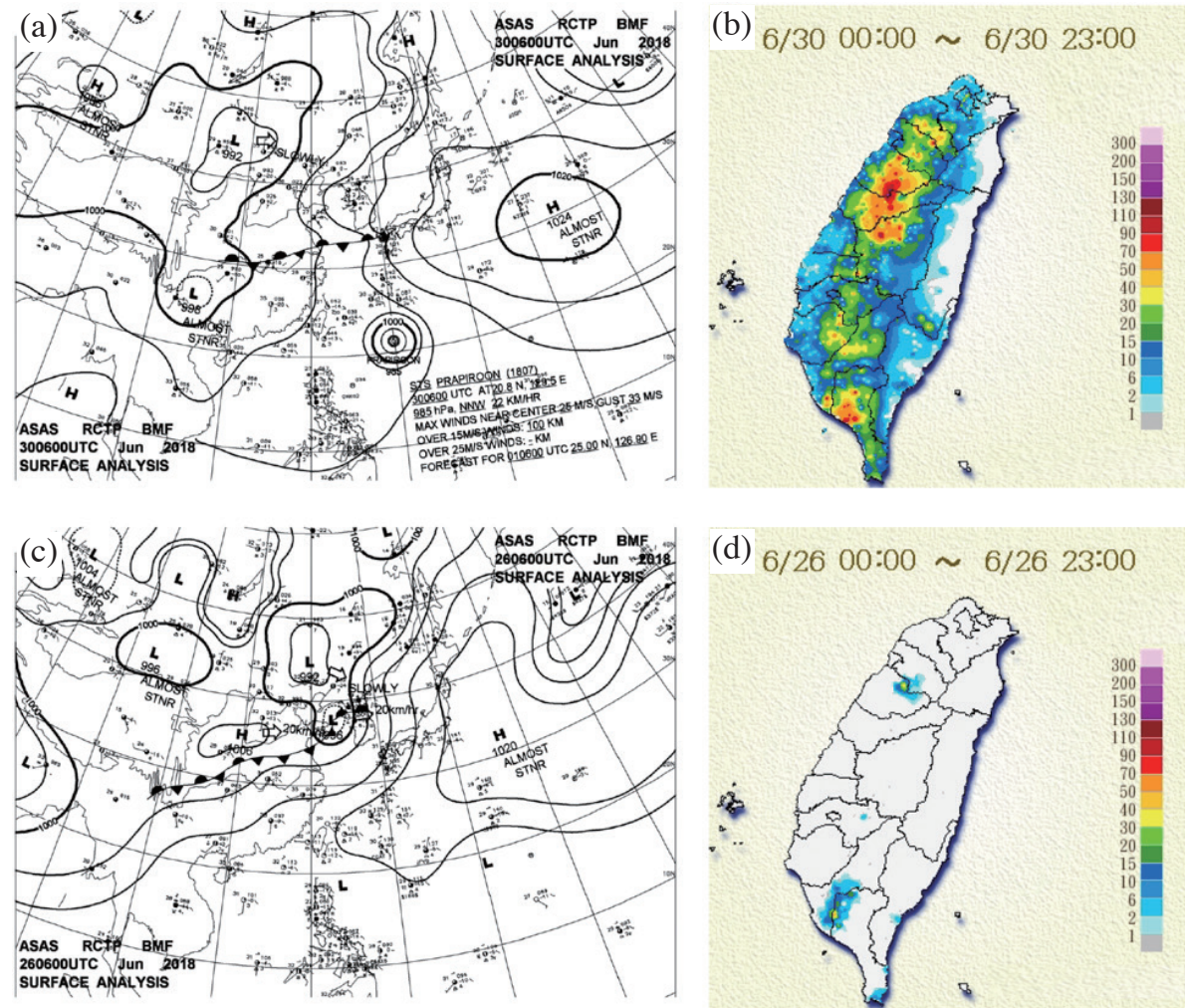

Fig. 1. (left) Surface weather charts at 1400 LST and (right) accumulated rainfall amount (shading, mm) of that day. The top and bottom panels correspond to 30 (TS) and 26 (NoTS) June 2018. All figures are from the CWB website (https://www.cwb.gov.tw/eng/).

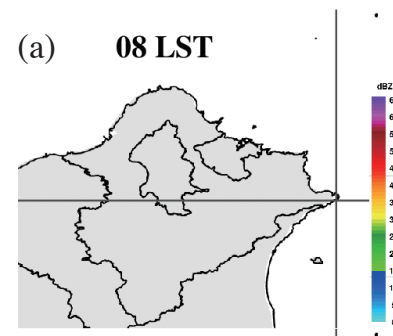

(b) $\quad 10$ LST

(d) 13 LST

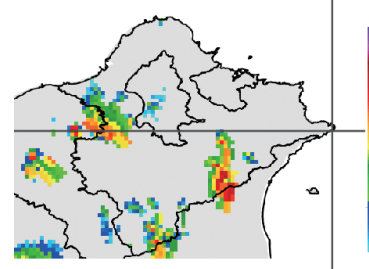

(g)

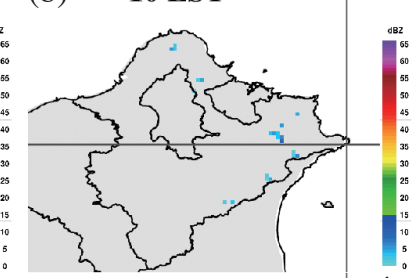

(c) 12 LST

(e)

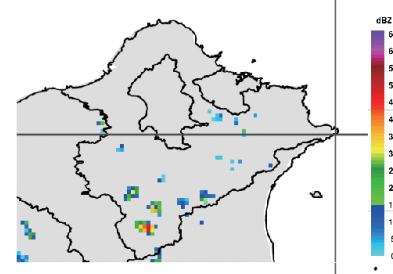

(f) 15 LST
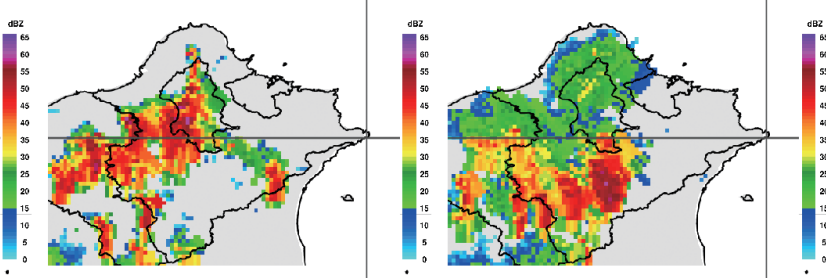

(h) $\quad 17$ LST
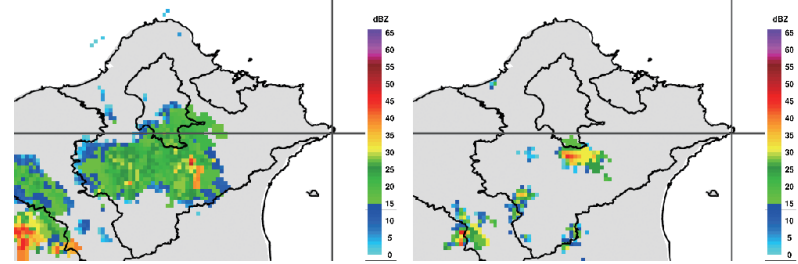

(i) $\quad 18$ LST

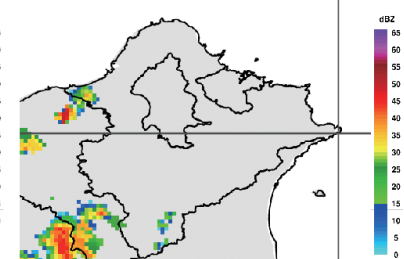

Fig. 2. The evolution of vertically maximum radar reflectivity observed by the CWB radar network for the TS case on $30 \mathrm{June} 2018$ (https://www. cwb.gov.tw/eng/). 
and Sakakibara 2002). This numerical model uses a terrainfollowing coordinate in vertical. It solves three-dimensional wind velocity components, pressure perturbation, potential temperature perturbation, turbulent kinetic energy (TKE), mixing ratios of water vapor, cloud water, rain, cloud ice, snow, and graupel, and number concentrations of the ice categories. The CReSS model has been used to study TSs in eastern Asia regions during summer seasons (e.g., Shinoda and Uyeda 2002; Sano and Tsuboki 2006; Yamada et al. 2007a, b; Yamada 2008). In particular, the model is also used in studies of TSs over Taiwan (e.g., Wang et al. 2014a, b, 2016, 2018).

Cloud microphysics scheme is an explicit bulk cold rain of a double moment for ice species (Murakami 1990; Murakami et al. 1994). Cumulus parameterization is not utilized in this model. Subgrid-scale turbulent mixing is parameterized using 1.5-order closure with TKE prediction (Deardorff 1980). On the bottom boundary, the temperature in the underground (including ground surface temperature) is predicted based on a one-dimensional thermal diffusive equation (Segami et al. 1989). Momentum and energy fluxes at the surface are formulated according to Kondo (1975) for the ocean and Louis et al. (1982) for land. Atmospheric and cloud radiation processes are calculated by a radiative scheme which is version 4.85 of the Rapid Radiative Transfer Model (RRTM-G) described in Mlawer et al. (1997) and Iacono et al. (2003).

\subsection{Experimental Design}

Numerical simulations with a horizontal resolution of sub-km scale are required to simulate convective-scale phenomena. According to previous studies (e.g., Wang et al. 2018), the one-way nesting method was used in the present study. The outermost domain (D1) had the horizontal grid spacing of uniformly $0.05^{\circ}$ in latitude-longitude coordinates as contained the subtropical high. The middle (D2) and innermost (D3) domains had the horizontal grid spacing of uniformly $1 \mathrm{~km}$ and $300 \mathrm{~m}^{1}$ with the Cartesian coordinates projected on a Lambert conical map as contained the entire Taiwan area (Fig. 3a). The vertical grid was in a stretching coordinate, with the upper boundary condition as a rigid lid. The model output of domain D3 was saved every 10 min for the analysis in this study.

The output of the Global Spectral Model provided by the Japan Meteorological Agency (JMA-GSM) was used as the initial and boundary conditions (IC/BC) in the three-dimensional atmosphere of domain D1. The data have 6-hourly output and horizontal resolution of $0.5^{\circ} \times 0.5^{\circ}$. In addition, the lateral boundary conditions of wave radiating with constant phase velocity were also imposed (e.g., Klemp and Wilhelmson 1978; Tsujino et al. 2017). The Shuttle Radar Topography Mission data with a horizontal resolution of 30 seconds from the U.S. National Aeronautics and Space Administration (SRTM30) were used for the terrain in all domains. In the simulation, no additional data assimilation was used. Details of the setting in each domain are listed in Table 1. Microwave Optimally Interpolated (OI) sea surface temperature (SST) data (Version 5.0 with MV and IR) produced by the Remote Sensing Systems were used as the SST distribution in the simulations.

\subsection{TASSE Data}

A newly-developed upper-air instrument, Storm Tracker (Hwang et al. 2020), was deployed during the TASSE. The Storm Trackers provide an unprecedented dataset of high-resolution (hourly temporal resolution, 1-hPa vertical resolution) vertical atmosphere profiles over the Taipei basin. Over 500 Storm Trackers and 114 operational Vaisala RS41 radiosondes were launched during the TASSE 2018. In addition, at the Banqiao site ("b" in Fig. 3b), the Storm Trackers were attached to the Vaisala RS41 radiosonde for intercomparison and data correction. This dataset from TASSE Storm Trackers had been validated with the Vaisala RS41 radiosondes and corrected accordingly.

The Storm Tracker radiosonde transmits its threedimensional position and velocity to the ground receivers every $1 \mathrm{~s}$ by receiving GPS satellite signals, the same as the Vaisala RS41 radiosonde. Meanwhile, information including pressure, temperature, and moisture were transmitted to the receiver. This new instrument was launched hourly at Shezi located in the northwestern valley of Taipei city ("s" in Fig. 3b) and Chidu located in the northeastern valley of the Taipei city ("c" in Fig. 3b) during 0800 LST to 1800 LST. Therefore, we can capture the evolution of BL structure of flow, temperature, and moisture associated with the sea-breeze circulation. It is known that onshore winds coming to the Taipei basin have two different wind directions of northeasterly and northwesterly during daytime (e.g., Chen et al. 2014), Thus the launching locations were designed to be able to capture these onshore winds.

Moreover, upward sondes were launched in operational times (0800 LST and 2000 LST) and additional time (1400 LST) at a CWB observatory of Banqiao ("b" in Fig. 3b) near the Taipei city during the TASSE period. The observation data can provide vertical profiles of horizontal wind, temperature, and moisture over the whole troposphere. In the present study, the data were treated as dynamic and thermodynamic structures in the environment.

1 Reproducibility of the convective clouds in numerical models highly depends on horizontal grid spacing (e.g., Miyamoto et al. 2013). Thus, we also examined enough model resolution to represent realistic convective clouds by conducting some sensitivity tests (not shown). 

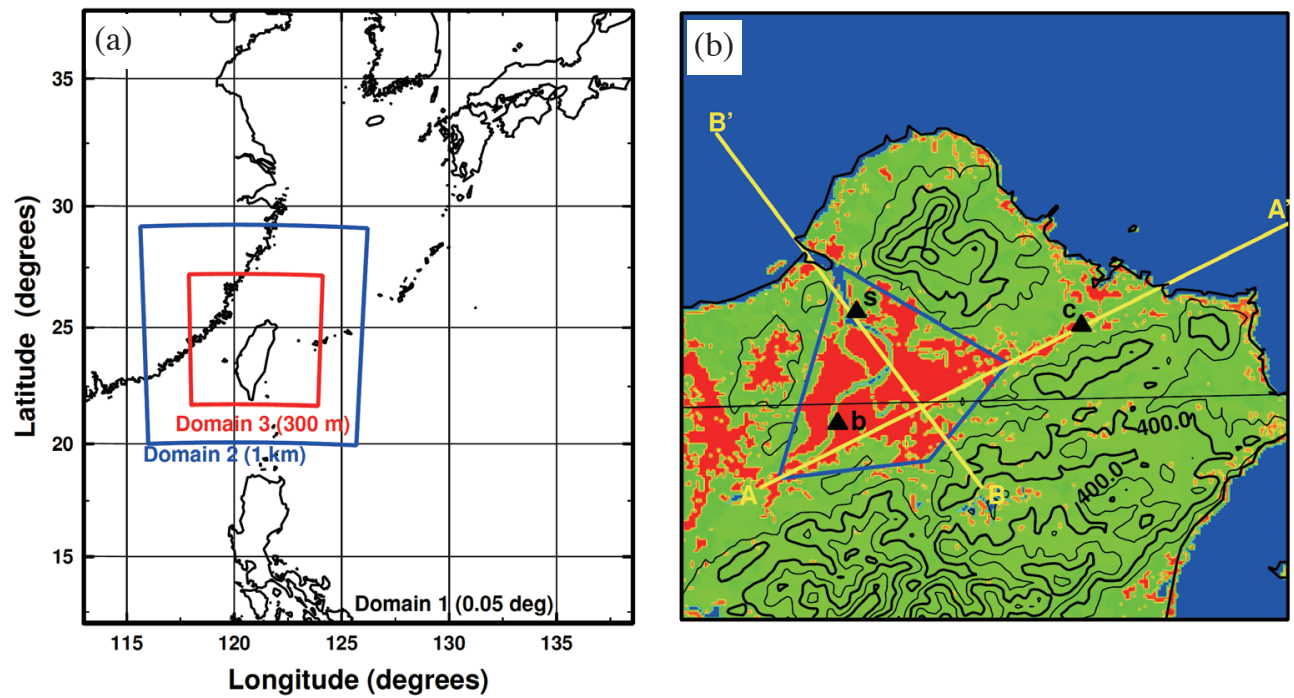

Fig. 3. (a) Model domain for the simulations. In panel (a), the whole region is D1 ( $0.05^{\circ}$ resolution), and regions enclosed by blue and red lines are D2 (1-km resolution) and D3 (300-m resolution), respectively. (b) launching points of Storm Trackers and radiosondes in the Taipei basin (blacktriangle markers; b: Banqiao; c: Chidu; s: Shezi). Cross-sections in Figs. 9 and 13 are along yellow lines A-A' and B-B'. Black contours denote the terrain at 200-m intervals. The region enclosed by blue lines denotes the area of areal averages of rainfall and horizontal water vapor flux convergence in Fig. 14.

Table 1. Experiment design of the real simulations.

\begin{tabular}{c|ccc}
\hline & D1 & D2 & D3 \\
\hline$\Delta x$ & $0.05^{\circ}$ & $1 \mathrm{~km}$ & $300 \mathrm{~m}$ \\
$\Delta z_{\min }$ & $200 \mathrm{~m}$ & $100 \mathrm{~m}$ & $20 \mathrm{~m}$ \\
Area & $25.6^{\circ} \times 25.6^{\circ}$ & $1024 \mathrm{~km} \times 1024 \mathrm{~km}$ & $614.4 \mathrm{~km} \times 614.4 \mathrm{~km}$ \\
Model top & $30 \mathrm{~km}$ & $25 \mathrm{~km}$ & $23 \mathrm{~km}$ \\
Vertical levels & 50 & 75 & 100 \\
Initial time & $2000 \mathrm{LST}$ & $0200 \mathrm{LST}$ & $0500 \mathrm{LST}$ \\
IC/BC & (the previous day) & (the target day) & (the target day) \\
Initial SST & JMA-GSM & Domain 1 & Domain 2 \\
Evolution of SST & 1D-model & Linear interpolation & Linear interpolation \\
Terrain & SRTM30 & SRTM30 & SRTM30 \\
\hline
\end{tabular}

\section{RESULTS BASED ON THE TWO REAL CASE STUDIES}

The realistic simulations on the TS and NoTS cases are verified by available observation. Figure 4 shows the accumulated rainfall amount in the simulations. For both cases, the simulated rainfall was qualitatively similar to that of the observation (Figs. 1b and d). The simulated rainfall had peaks over $70 \mathrm{~mm}$ in the central and southern parts of Taiwan on the TS case (Fig. 4a). Similar peaks over $70 \mathrm{~mm}$ were observed in the rain gauge (Fig. 1b).

On the other hand, the simulation overestimated the rainfall in the eastern and northeastern mountain region of Taiwan for the TS case (Fig. 4a). Focused on the Taipei basin, the simulation reasonably captured the observation in both cases. In particular, some local rainfall peaks around 30 to $40 \mathrm{~mm}$ occurred in the Taipei basin for the TS case (Fig. 4b), similar to that of the observation.

Moreover, the evolution of the simulated TS clouds around the Taipei basin was verified by observation in the radar network. Figure 5 shows the maximum radar reflectivity in each vertical column based on the CReSS simulation. In the morning, there were weak echoes around the Taipei basin (Figs. 5a, b). Some isolated convective clouds formed around the Taipei basin during 1200 to 1300 LST (Figs. 5c, d). The isolated clouds gradually concentrated in the Taipei basin and organized at 1400 LST (Fig. 5e). At 1500 LST, the organized clouds are achieved at the mature 
stage of a cumulus cloud (Fig. 5f). Then, the well-developed clouds gradually decayed after 1600 LST (Figs. 5g, h, i). The evolution of the TS clouds in the simulation was similar to that of the observation (Fig. 2). On the other hand, the timing (1500 LST) of the mature stage in the simulation had slightly delayed, compared with that (1400 LST) of the observation (Fig. 2).

Other active convective clouds also formed around the northeastern mountain region in the afternoon (Fig. 5f). However, the clouds were not formed in the observation (Fig. 2f). The simulated rainfall amount was overestimated due to unreal clouds around the mountain region (Figs. 1d and 4d).

\subsection{Boundary Layer}

As Johnson and Bresch (1991) proposed that the afternoon TSs can be formed associated with the sea-breeze circulation around the Taipei basin, we are interested in the horizontal winds near the surface. For the TS simulation, offshore wind was simulated from the Taipei basin to northeastward and northwestward directions in the early morning (Fig. 5a). The wind directions returned around 1000 LST, and the onshore wind was coming to the Taipei basin around 1200 to 1300 LST (Figs. 5b, c, and d). Coin- cided with the arrival of the onshore wind, some convective clouds formed around the Taipei basin. The clouds gradually organized as the onshore wind enhanced during 1400 to 1500 LST (Figs. 5e and f). After 1600 LST, new convective clouds formed around the original well-developed clouds (Fig. $5 \mathrm{~g}$ ). Note that the new clouds in the simulation did not appear in the observation (Fig. 2g).

The offshore wind in the morning is also properly simulated for the NoTS case (Fig. 6a). The wind directions returned around 1000 LST (Fig. 6b) and dominated the Taipei basin around 1400 LST in the afternoon (Figs. 6c - e). Although clear sea-breeze circulation was formed around the Taipei basin, the organization of the afternoon TSs and heavy precipitation were not observed over the Taipei basin for the NoTS case. In the afternoon, the southeasterly wind dominated the ocean (Figs. $6 \mathrm{c}-\mathrm{i}$ ). The southeasterly wind originated from synoptic-scale circulations associated with the subtropical high above the BL. After 1700 LST, an elongated pattern of weak radar reflectivity was located along the mountain range (Figs. 6h, i), which is due to the concentration of the snow in a layer of 12- to 14-km heights (not shown). As the elongated pattern is approximately normal to the prevailing southeasterly wind, we speculate that this elongated pattern can be mainly due to mountain waves (a) 30 June 2018

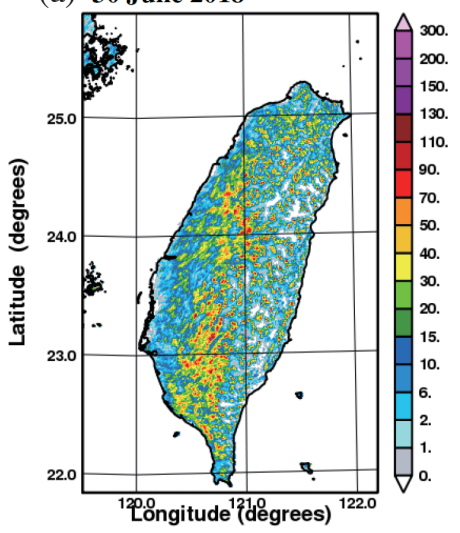

(c) 26 June 2018

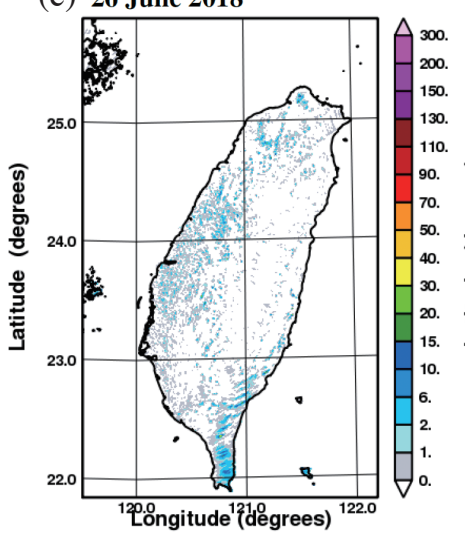

(b) 30 June 2018

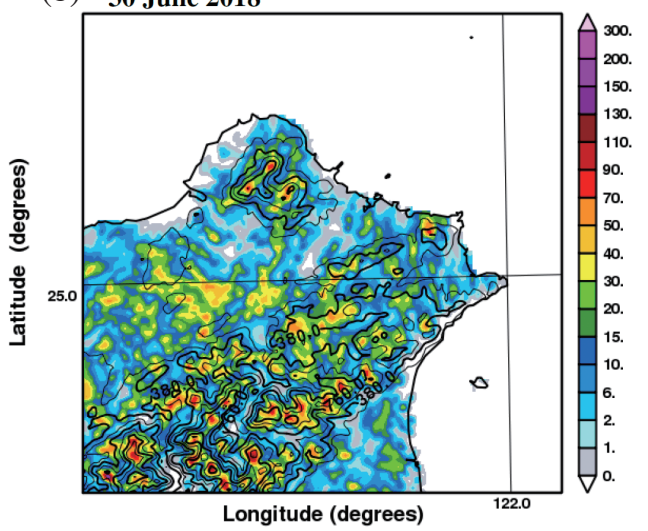

(d) 26 June 2018

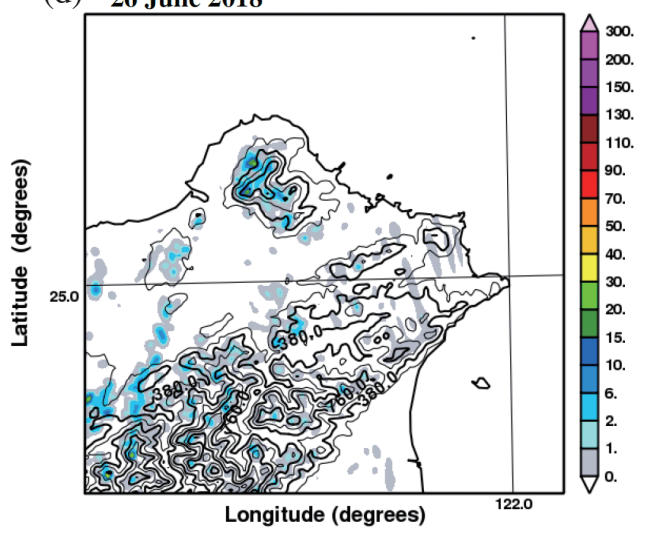

Fig. 4. Simulated accumulated rainfall (color; mm) from 0500 LST to 1800 LST on (top) 30 and (bottom) 26 June 2018. Right panels focus on the Taipei basin, and the contours indicate terrain height (m). 
(a) 08 LST

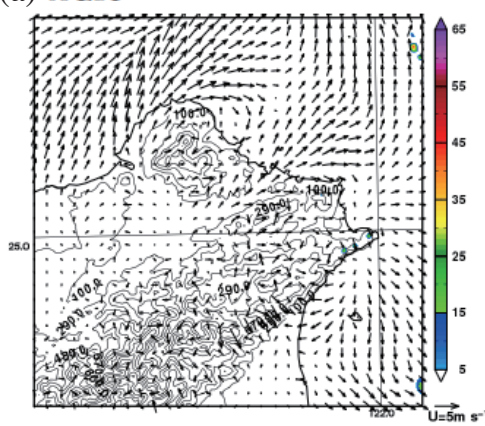

(d) 13 LST

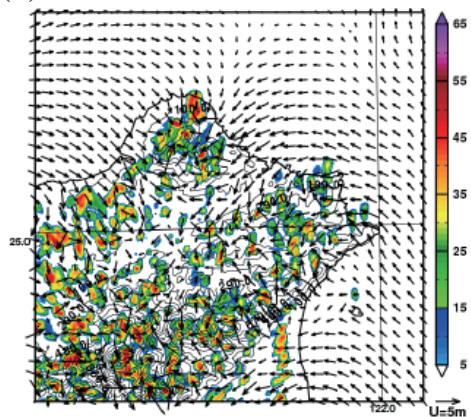

(g) 16 LST

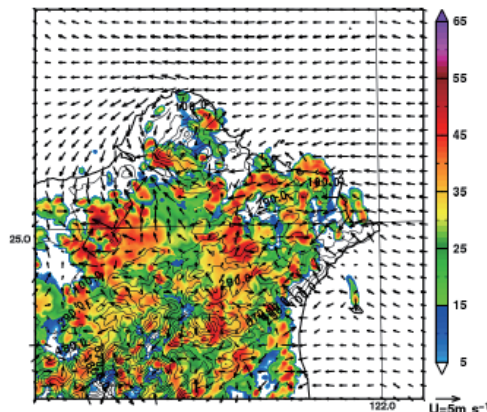

(b) 10 LST

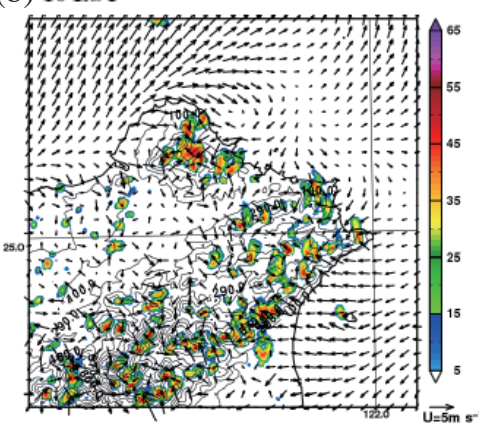

(e) 14 LST

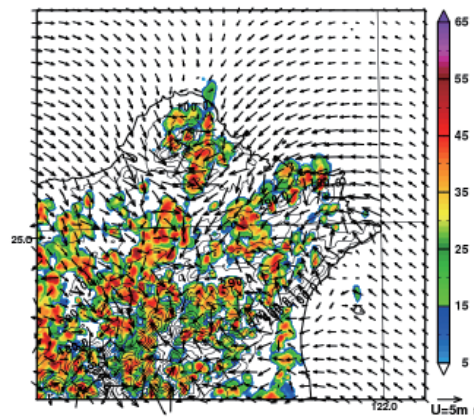

(h) 17 LST

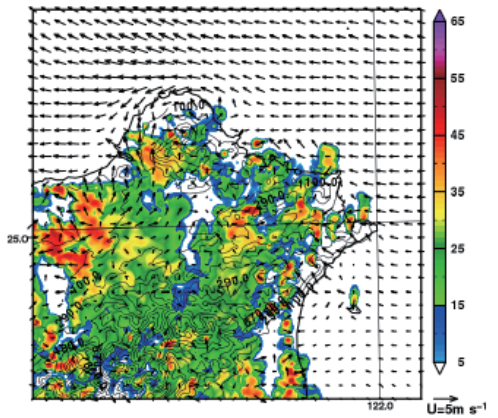

(c) 12 LST

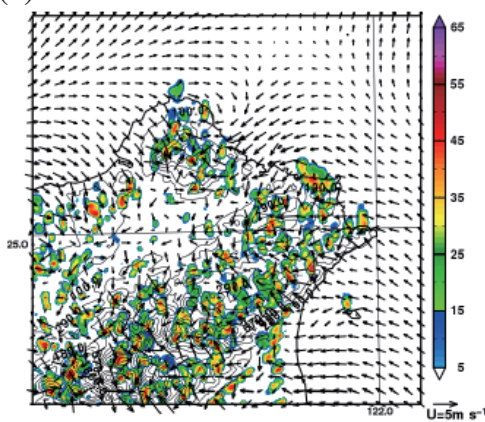

(f) 15 LST

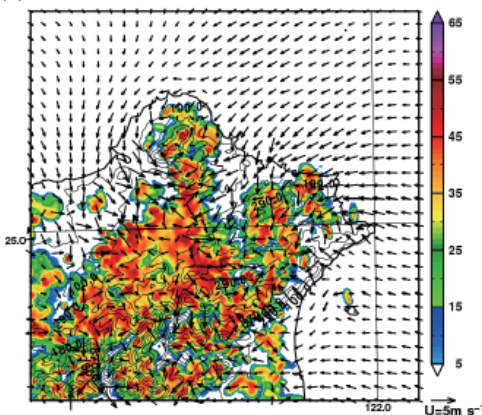

(i) 18 LST

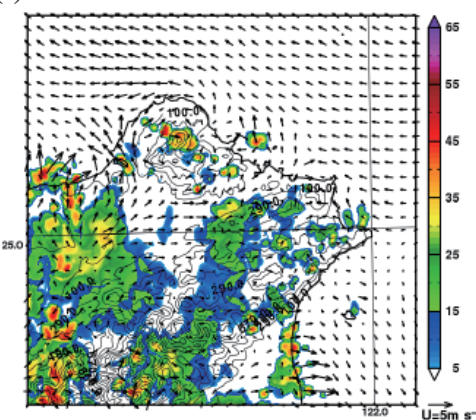

Fig. 5. The maximum radar reflectivity (shading; dBZ), terrain height (contours with 200-m intervals) and 10-m wind vectors in Domain 3 at (a) 0800 LST, (b) 1000 LST, (c) 1200 LST, (d) 1300 LST, (e) 1400 LST, (f) 1500 LST, (g) 1600 LST, (h) 1700 LST, and (i) 1800 LST on 30 June 2018. 
(a) 08 LST

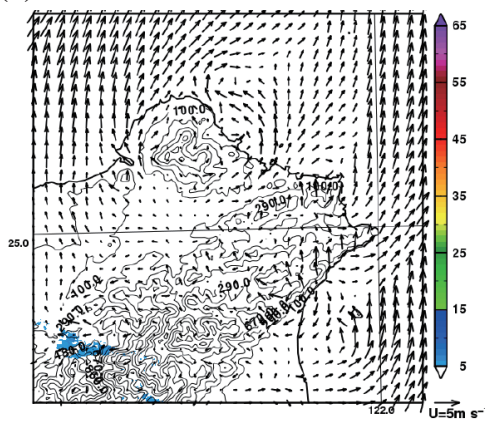

(d) 13 LST

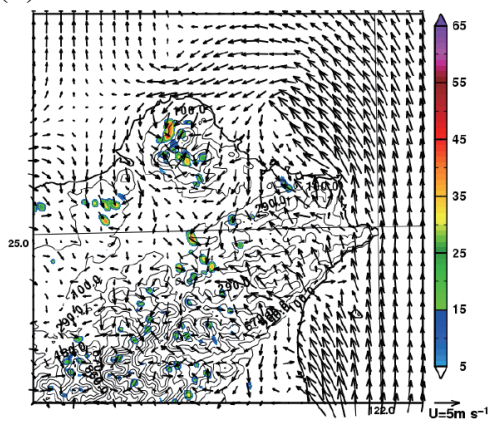

(g) 16 LST

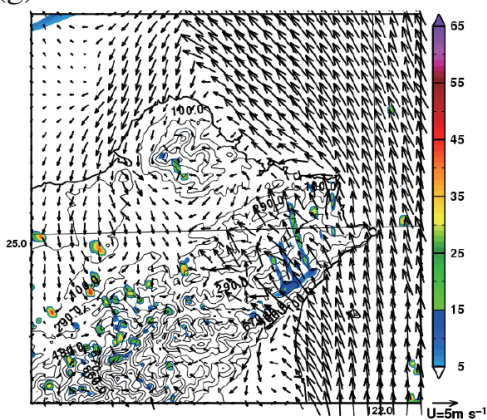

(b) 10 LST

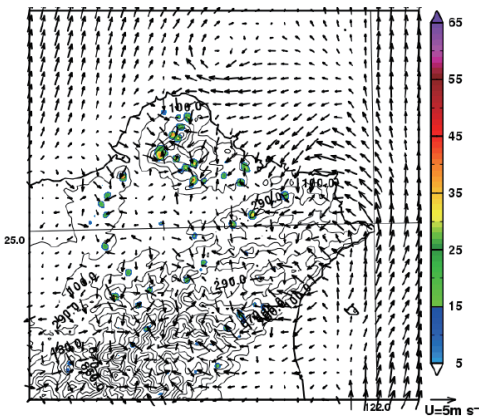

(e) 14 LST

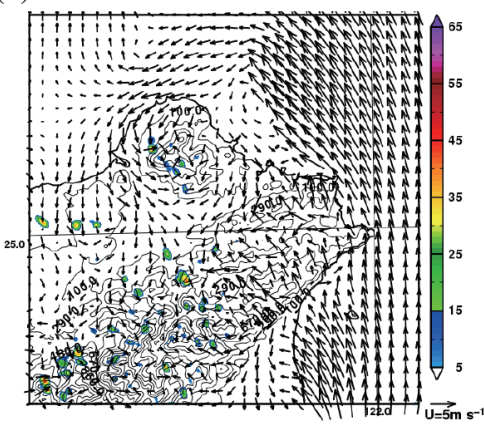

(h) 17 LST

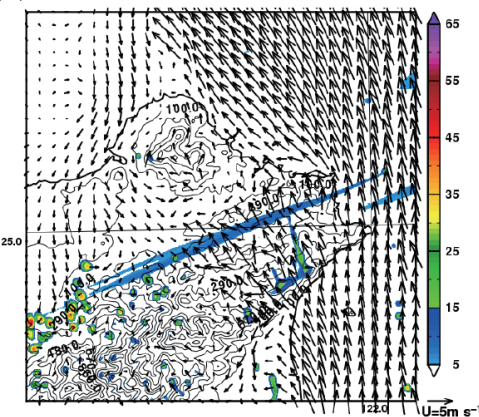

(c) 12 LST

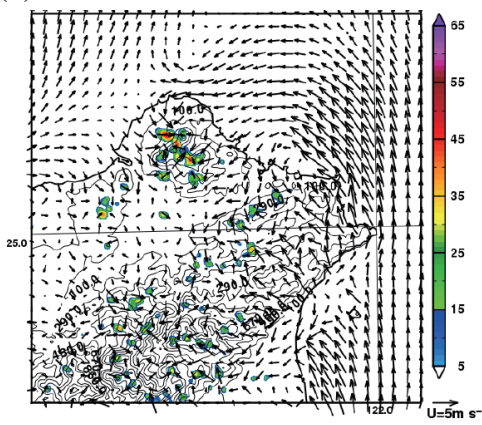

(f) 15 LST

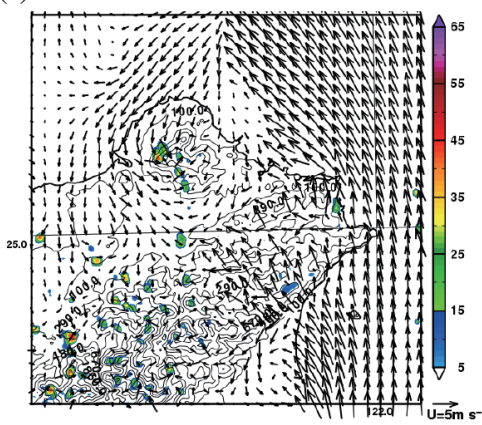

(i) 18 LST

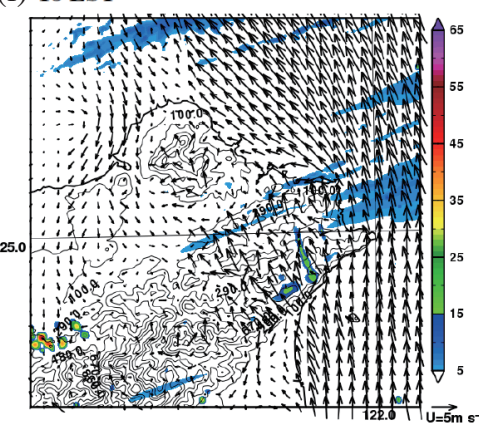

Fig. 6. As in Fig. 5, except for the case on 26 June 2018. 
associated with the prevailing wind. It is a discrepancy in the model simulation; however, the elongated pattern appeared near the end of the simulation. Thus, this discrepancy might not be critical for most of the analysis in this study.

The Storm Tracker verifies the evolution and distribution of the simulated circulation within the BL. For both cases, northwesterly winds were observed below a height of $300 \mathrm{~m}$ at Shezi at $1200 \mathrm{LST}$ (Figs. 7a, e). The top height of the northwesterly layer achieved around $800 \mathrm{~m}$ in 1400 to 1500 LST. Similarly, the development of the northeasterly layer was observed at Chidu at 1200 LST (1100 LST) in the NoTS (TS) case, as shown in Fig. 7c (Fig. 7g). For the TS case, the top height of the northeasterly layer achieved about $1000 \mathrm{~m}$ (Fig. 7g). Shezi and Chidu are located northwest and northeast of the Taipei basin, respectively. The northwesterly and northeasterly layers indicate the seabreeze circulation. The structure and evolution of the seabreeze circulation for both cases were qualitatively captured in the numerical simulations (Figs. 7b, d, f, h). For the TS case, changes (1200 LST) of the wind direction associated with the simulated sea-breeze incoming delayed about $1 \mathrm{~h}$, compared with the observations (1000 - 1100 LST). The delay in the simulation corresponds to the slightly late timing of the simulated mature clouds, as mentioned previously.

In the simulations, equivalent potential temperatures $\left(\theta_{e}\right)$ representing temperature and moisture were underestimated within the BL, due presumably to the underestimation of $\theta_{e}$ in the initial JMA-GSM data produced by the coarseresolution global model. Nevertheless, the evolution of the simulated $\theta_{e}$ was similar to the observation. In particular, the gradual deepening of high $-\theta_{e}$ layer in the afternoon was reasonably reproduced in the simulations. For the NoTS case, an upward steep decrease of $\theta_{e}$ around a height of 2000 $\mathrm{m}$ was observed at both launching points in the afternoon (Figs. 7a, c). Of interest is that the organization of the afternoon TSs was not exhibited on the NoTS case despite this feature referred to as convective instability (e.g., Lin 2007). The high $-\theta_{e}$ layer within the BL was fully capped by the lower $\theta_{e}$ air mass above the 2000-m height in the afternoon (Fig. 7a), being captured in the simulation as well (Fig. 7b). In contrast to the similarity of the thermal structure within the BL for both cases, the thermal structure above the 2000$\mathrm{m}$ height was quite different (Figs. 7a, c, e, g).

\subsection{Free Atmosphere}

The time series of the Storm Trackers also captured the evolution of horizontal wind in the free atmosphere. For the NoTS case, southerly to southeasterly wind exceeding about $7 \mathrm{~m} \mathrm{~s}^{-1}$ dominated above 1-km height (Figs. 7a, c), associated with the southwestern edge of the subtropical high (Fig. 1a). The simulation had slightly stronger southerly than the observation (Figs. 7b, d). For the TS case, southerly to southwesterly wind dominated above $1-\mathrm{km}$ height
(Figs. 7e, g), associated with a low-pressure synoptic system over China (Fig. 1c). Westerly components of simulated flows were weaker than that of the observation (Figs. 7f, h), which was similar to the JMA-GSM used as the initial and boundary conditions in domain D1 (not shown).

Additional upper soundings observed winds and thermal fields in the middle and upper troposphere during the TASSE campaign. For the NoTS case, there was a clear inversion layer above a pressure level of $800 \mathrm{hPa}$ (Fig. 8a), and the inversion layer leads to small convective available potential energy (CAPE). Above the inversion layer, there was dominated by dry layers with relatively low dew-point temperature to a $200-\mathrm{hPa}$ level. It indicates that the low$\theta_{e}$ layer observed in the Storm Tracker on the NoTS case was mainly due to the dry airmass. It can be associated with subsidence in the subtropical high. The simulation captured a similarly dry layer above the $800-\mathrm{hPa}$ level, although it failed to simulate the strong inversion layer at the $800-\mathrm{hPa}$ level (Fig. 8b). In contrast to the NoTS case, the free atmosphere in the TS case had more moist air (Fig. 8c), consistent with Lin et al. (2011b). The moist airmass can be supplied by moisture transport associated with the synoptic southwesterly, and it was simulated in the CReSS model (Fig. 8d). The difference in the middle-level moisture between the NoTS and TS cases is also clearly shown in precipitable water of Figs. 8a, c (Figs. 8b, d) in the observations (in the simulations). On the other hand, the moisture profiles between NoTS and TS cases were not largely different below the level of $800 \mathrm{hPa}$, consistent with the Storm Tracker observation (Figs. 8a, c). Note that the CAPE during the afternoon in the TS case was not so large because the sounding profile in Fig. $8 \mathrm{c}$ can be observed after the instability for the convection was somewhat released.

\subsection{Structure of TS Clouds}

Figure 9 shows the structure and evolution of the simulated TS clouds developing in the Taipei basin on the TS case. In the morning, shallow convections with local high- $\theta_{e}$ appeared below $2-\mathrm{km}$ height in the Taipei basin, which is located at horizontal distances from 16 to $32 \mathrm{~km}$ along the A-A' cross-section in Fig. 9a. Relatively deep convections were also generated in the Taipei basin, located at horizontal distances from 20 to $30 \mathrm{~km}$ along the B-B' cross-section in Fig. 9d. After the sea breeze reached inland, deep convections rapidly developed around the Taipei basin in the afternoon (Figs. 9b, e). Each convection had a horizontal scale of 4 - $5 \mathrm{~km}$ (Fig. 9e). The echo-top height, defined as the maximum height of model grids with $15 \mathrm{dBZ}$, reached at 10-km height (Fig. 9b). At 1700 LST, the deep convections gradually decayed in the Taipei basin, and the structure indicated characteristics of stratiform clouds rather than convective clouds (Figs. 9c, f).

For the NoTS case, shallow convections appeared 

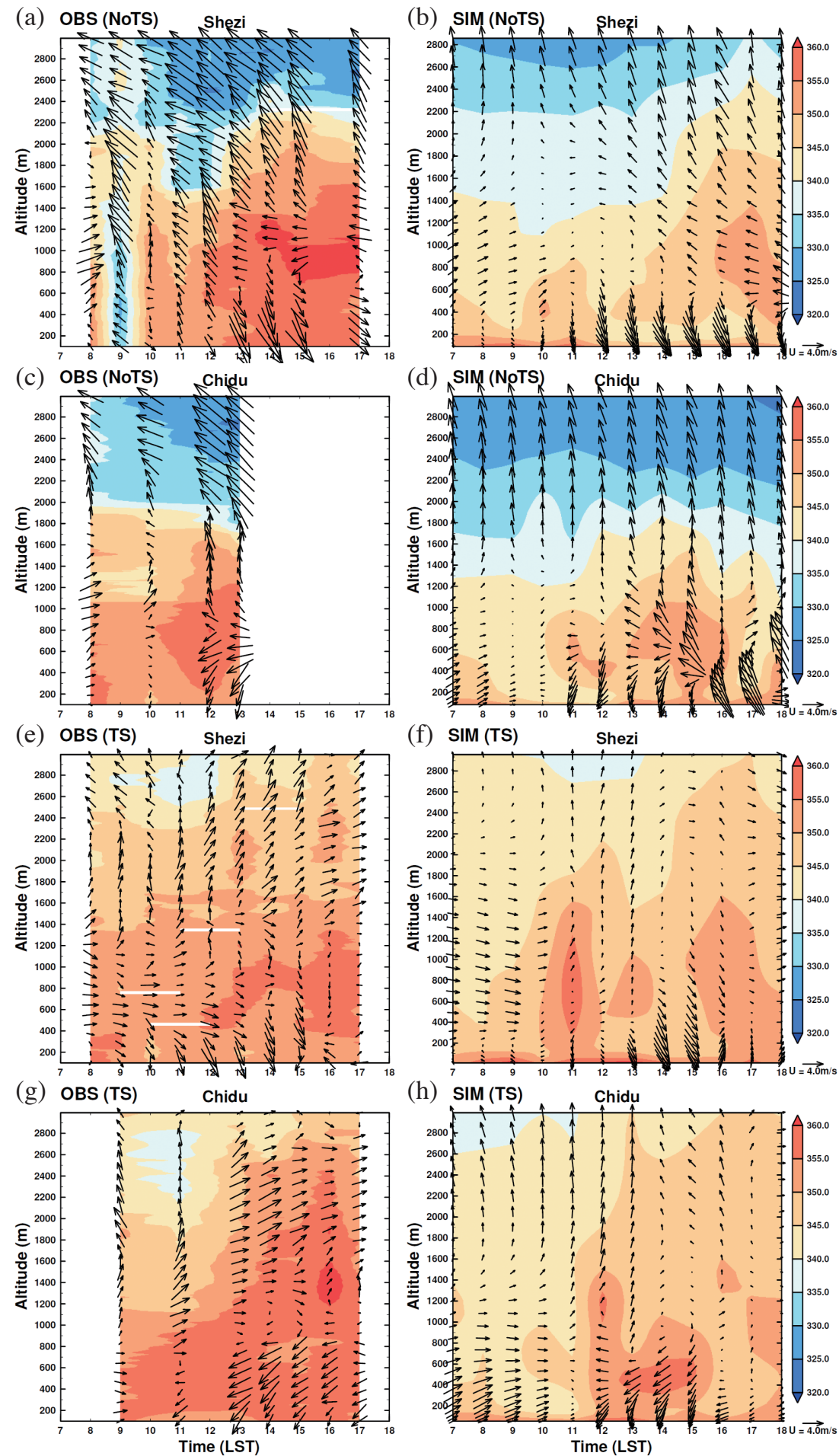

Fig. 7. Time-height cross-sections of horizontal winds and $\theta_{e}$ (shading; K) for the TASSE observation (left) and the CReSS simulation (right). Panels (a) - (d) and (e) - (h) are on 26 and 30 June 2018, respectively. (a), (b), (e), (f) are the profiles at Shezi ("s" in Fig. 3b), and (c), (d), (g), (h) are the profiles at Chidu ("c" in Fig. 3b). 

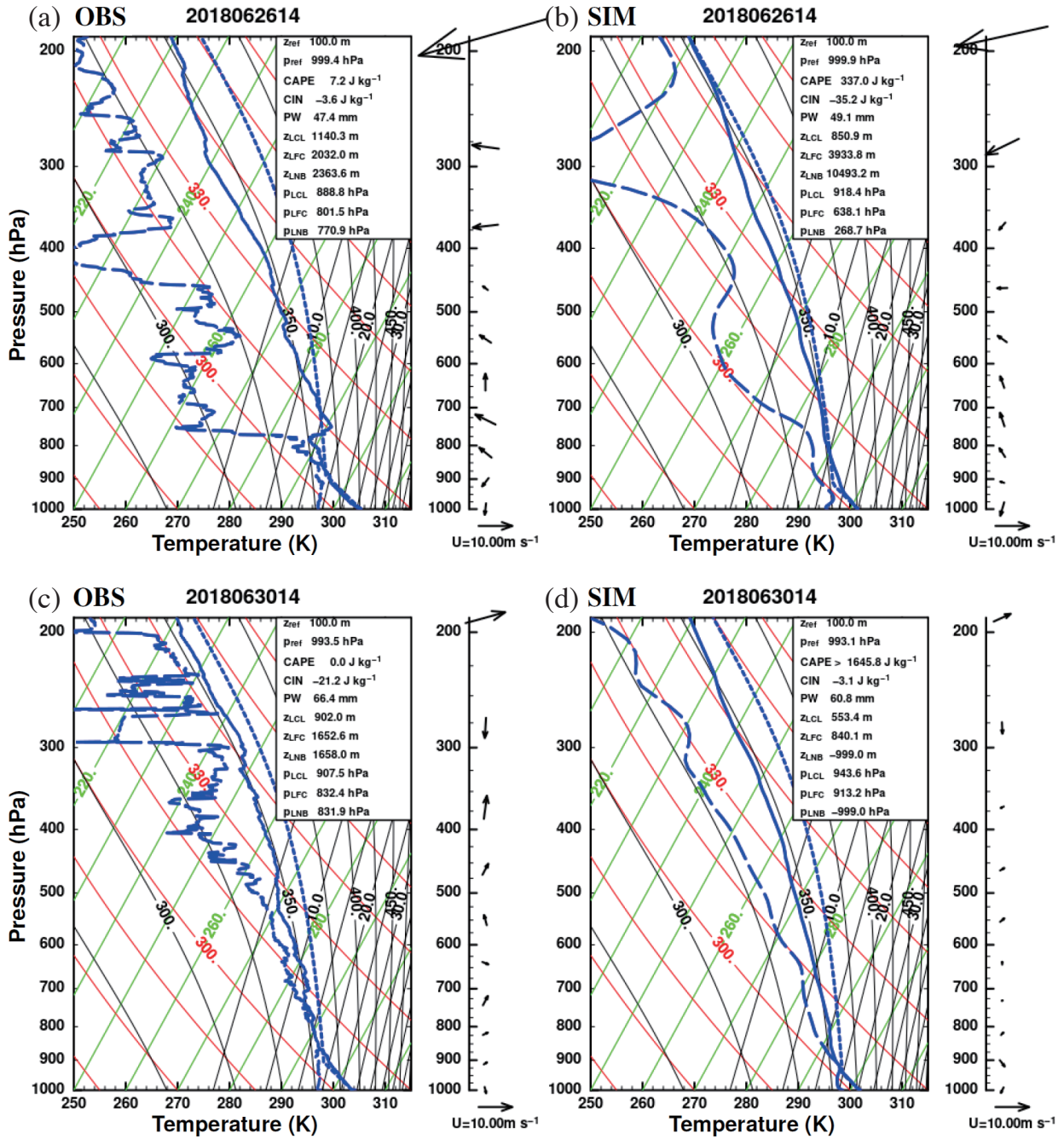

Fig. 8. SkewT- $\log$ P diagrams at Banqiao station (Fig. 3b, "b") for the observation (left) and the simulation (right). The top and bottom panels are at 1400 LST 26 and 1400 LST 30 June 2018, respectively. Blue solid and dashed lines denote vertical profiles of temperature and dew-point temperature, respectively. The blue dotted line denotes the temperature of the parcel, which is lifted along the dry adiabat from the surface to the lifted condensation level (LCL), then along the moist adiabat to the top. Black, red, and green solid lines denote moist adiabats, dry adiabats, and isotherms. Black dashed line denotes contour of saturated water vapor mixing ratio. Some convective parameters such as CAPE, convective inhibition (CIN), precipitable water (PW), LCL, level of free convection (LFC), and level of neutral buoyancy (LNB) are calculated in the top right of each panel. 
(a) 11 LST $\quad$ TS

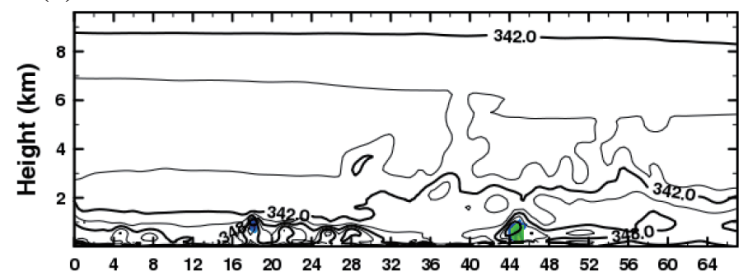

(b) 14 LST

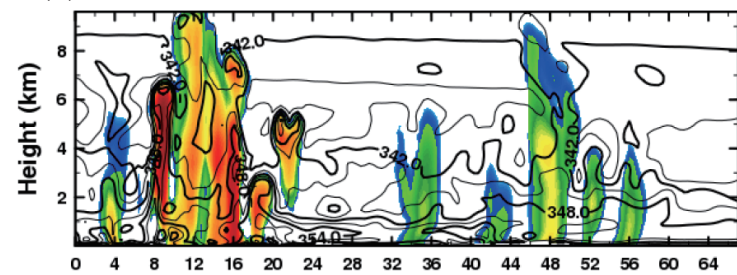

(c) 17 LST

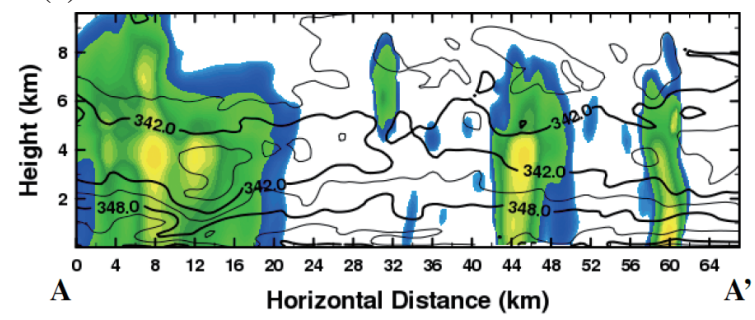

(d) 11 LST

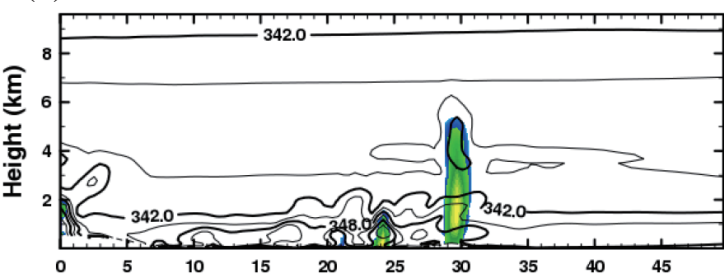

(e) 14 LST

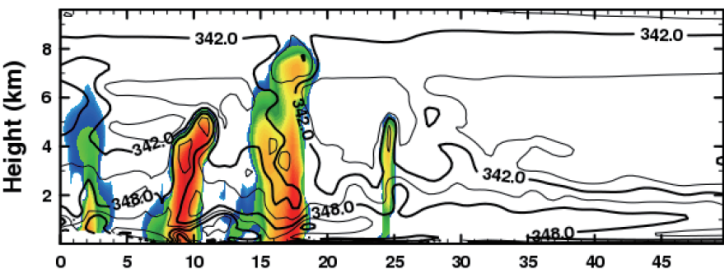

(f) 17 LST

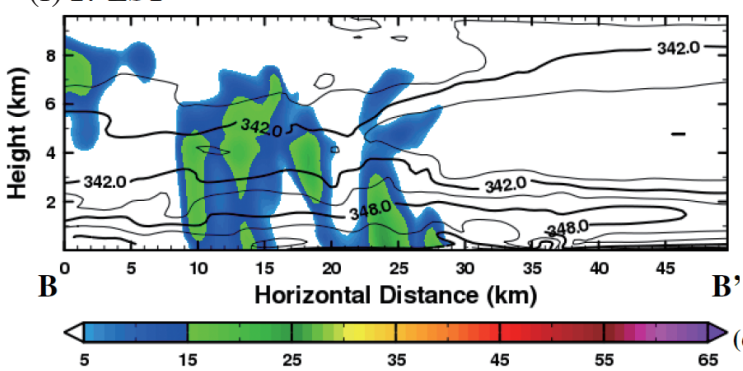

(g) 11 LST

NoTS

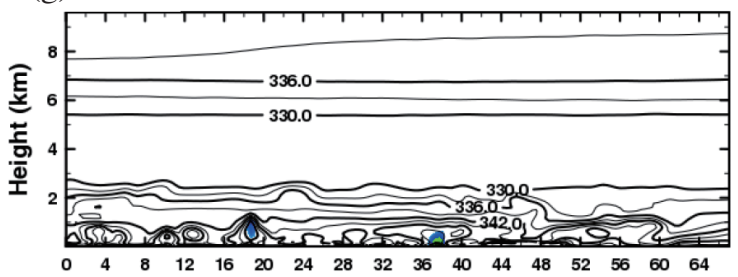

(h) 14 LST

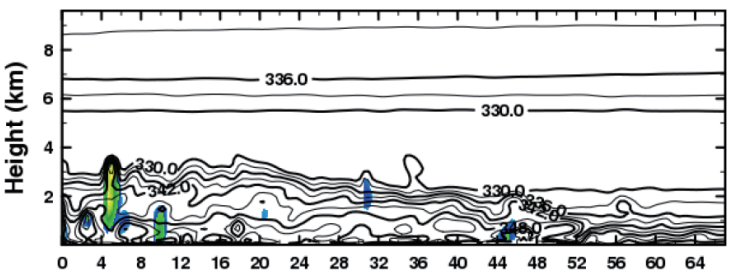

(i) 17 LST

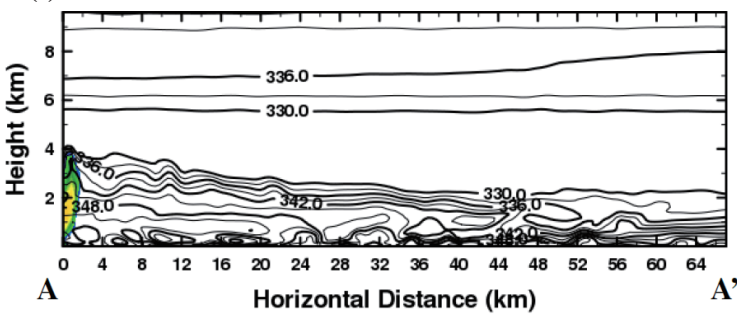

(j) 11 LST

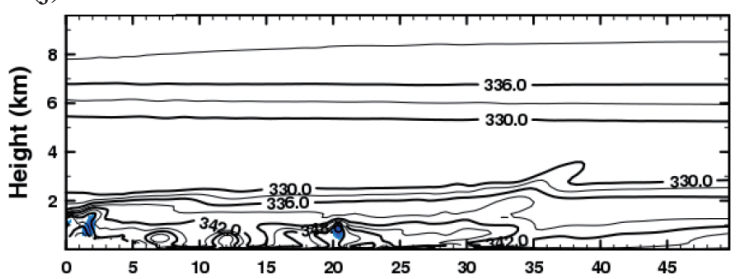

(k) 14 LST

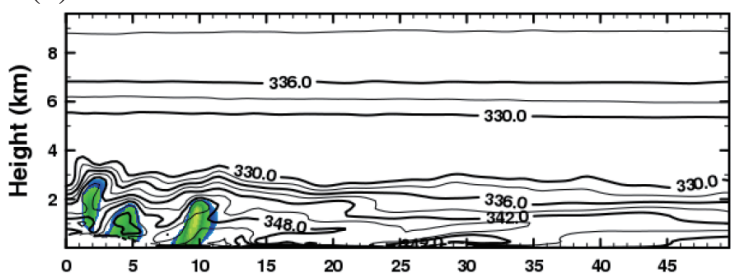

(1) 17 LST

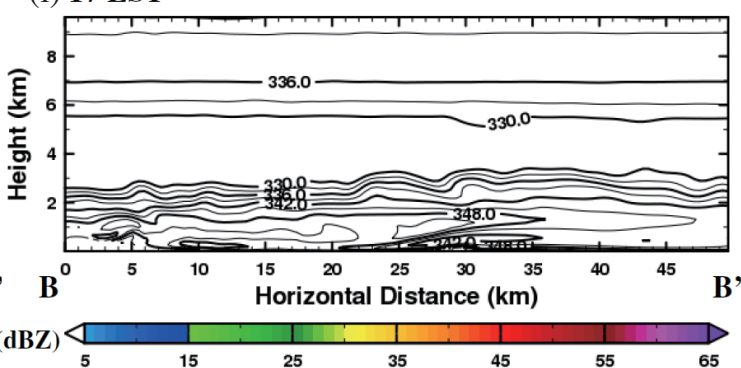

Fig. 9. Simulated vertical cross-sections of radar reflectivities (shading; dBZ) and $\theta_{e}$ (contour; K) along with A-A' (upper six panels) and B-B' (lower six panels) as indicated in Fig. 3b. The left and right panels correspond to 30 and 26 June 2018, respectively. 
below 2-km height in the morning, as with the TS case (Figs. 9g, j). In contrast to the TS case, the convections did not develop and organize in the afternoon (Figs. 9h, k). A layer with low $\theta_{e}$ less than $330 \mathrm{~K}$ was capping on the $\mathrm{BL}$, consistent with observations in the upper sounding and Storm-Tracker. Moreover, we recall the southeasterly flows associated with the subtropical high in the Taipei basin for the NoTS case. The southeasterly layer overlaps with the dry layer, and the flows continued to supply fresh dry air over the Taipei basin. Although high- $\theta_{e}$ airmass associated with shallow convections was transported to the middle troposphere around the mountain regions at 1400 LST along the approximately southeast to northwest cross-section (from 0 to $12 \mathrm{~km}$ along the B-B' in Fig. 9k), the high- $\theta_{e}$ air mass did not remain in the middle layer at 1700 LST (Fig. 91).

\section{IDEALIZED SIMULATIONS EXAMINING THE ROLE OF VENTILATION}

\subsection{Hypothesis}

According to the comparison between the NoTS and TS cases in the BL and free atmosphere, we found apparent differences of moisture and wind profiles in the middle troposphere despite clear sea-breeze incoming to the Taipei basin in both cases. For the NoTS case, the dry layer with strong southeasterly flows was capped on the BL. The dry-layer capping can reduce convective buoyancy by exchanging air masses between convective clouds and the environment (i.e., entrainment). Moreover, southeasterly wind associated with the dry layer can supply the dry air mass to the Taipei basin. The continuous supply can keep the entrainment.

Although our simulation did not simulate the strong inversion layer at the $800-\mathrm{hPa}$ level on the NoTS case, the simulated rainfall amount associated with the afternoon TSs was qualitatively consistent with the rain gauge (Figs. 1b and 4a). Thus, we focus on possible factors for the organization of the afternoon TSs, except for the inversion layer. It does not mean that the inversion layer is not important for the afternoon TSs. Further examination of the quantitative contribution of the inversion layer to the afternoon TSs is left for future studies.

We hypothesize the roles of the environment on the TS development as follows: (i) environmental moisture field above the BL can control the development through entrainment between clouds to the environment, and (ii) environmental wind field above the BL can help to keep the entrainment through the continuous supply of the dry airmass. For (i), Shinoda and Uyeda (2002) pointed out that middle-level environmental moisture can be an influential factor in developing deep convective clouds over eastern China during a summer monsoon season. For (ii), the wind field can encourage entrainment in the developing clouds by acting as a kind of "ventilation" and suppressing development. The environmental winds' role for the afternoon TSs is newly pointed out in the present study. Note that the term "ventilation" is quite different from Chen et al. (2014); in their paper, it is used in airmass exchange over the Taipei basin between daytime (sea breeze) and nighttime (land breeze). Additional sensitivity experiments under more idealized situations are performed to examine these factors independently.

\subsection{Configuration of Idealized Experiments}

Sensitivity experiments are performed to isolate and examine the individual role of middle-level moisture and prevailing flows in the environment to the TS organization. These experiments were performed with only the domain D3. The design of the experiments is the same as in the real simulations, except for the different initial and boundary conditions and initial time on a $f$-plane ${ }^{2}$ centered at $25^{\circ} \mathrm{N}$. The temperature and moisture profiles in the sensitivity experiments are initialized by upper soundings launched at Banqiao at 0800 LST 26 (NoTS) and 0800 LST 30 (TS) June 2018 (Fig. 10). Note that the initial time is at 0200 LST on the days. We recognize a gap of $6 \mathrm{~h}$ between the initialization time in the model experiments and the sounding observation used in initial conditions, as real soundings at 0200 LST are not available ${ }^{3}$.

The horizontally uniform temperature and pressure profiles were given in the experiments with no prevailing wind at the initial time. In contrast, the temperature and pressure profiles in the simulations with the prevailing wind had horizontal variation following the gradient wind balance. The horizontally uniform moisture profile is given at the initial time in all of the idealized simulations. Also, the model boundary conditions in the experiments were fixed at the initial time.

Two experiments associated with the NoTS and TS sounding are conducted with no environmental flow, named NoTS-NoSE and TS-NoSE, respectively. The other two experiments are conducted with an analytical profile of horizontally uniform wind in a steady-state, named NoTSSE and TS-SE, respectively (Table 2). The horizontal wind profile $(\boldsymbol{U})$ is expressed as the following:

\footnotetext{
2 Although we focus on convective-scale simulation, a setting of the f-plane is needed still. The Coriolis force can reduce the strength of sea-breeze circulation (e.g., Miller et al. 2003).

3 We performed the idealized simulations with different initialization times using the same initial condition to check the model spin-up time needed in the idealized simulations, in advance. In case of the initialization time of 0800 LST, the development of the sea-breeze circulation tends to be delayed and weak, compared with the case of the initialization time of 0200 LST. The delay in the case of the initial time at 0800 LST can be due to no wind below 2-km height at the initial conditions.
} 

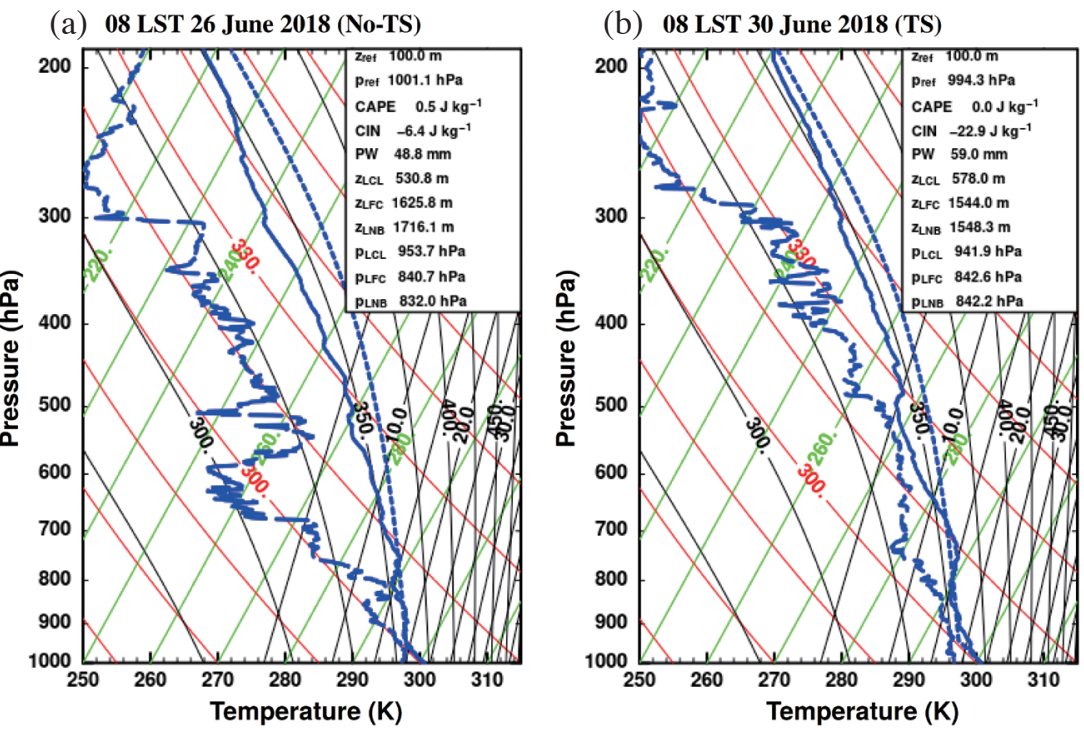

Fig. 10. Similar to Fig.8, except for the initial conditions for the idealized experiments based on the Banqiao soundings at 0800 LST on (a) 26 and (b) 30 June 2018.

Table 2. A list of the four idealized experiments.

\begin{tabular}{c|ccc}
\hline & Thermodynamic profile & Environmental flow & Initial time \\
\hline NoTS-NoSE & 0800 LST 26 June 2018 & 0 & 0200 LST 26 June 2018 \\
TS-NoSE & 0800 LST 30 June 2018 & 0 & 0200 LST 30 June 2018 \\
NoTS-SE & 0800 LST 26 June 2018 & $\boldsymbol{U}(z)$ & 0200 LST 26 June 2018 \\
TS-SE & 0800 LST 30 June 2018 & $\boldsymbol{U}(z)$ & 0200 LST 30 June 2018 \\
\hline
\end{tabular}

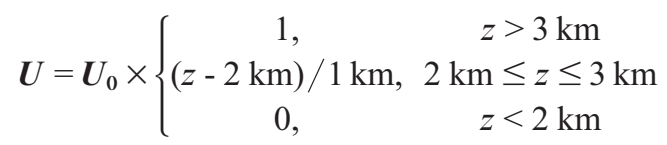

Where $\boldsymbol{U}_{\mathbf{0}}=(-6,4)$. This analytical profile is based on a real horizontal wind profile observed by the Banqiao sounding at 0800 LST on 26 June 2018. Note that the observed wind profile cannot present any steady states due to highly vertical fluctuation and helicity because the horizontal wind with any helicities does not allow our setting on the $f$-plane to maintain the steady-state environment. The mathematical proof is shown in Appendix. Thus, the profile of Eq. (1) with no helicity is given in the present study. Other variables such as condensates and vertical velocity were set as zero at the initial time.

\subsection{Role of Middle-Level Moisture}

The role of middle-level moisture in organizing afternoon TSs is examined by comparison between NoTSNoSE and TS-NoSE. First, an overview of the simulations is shown as the accumulated rainfall. Under no environ- mental flow, the total rainfall in NoTS-NoSE was qualitatively similar to that in TS-NoSE (Figs. 11a, b). The clear sea breeze and afternoon TSs were simulated in both cases (Figs. 12a, b). Note that the horizontal scale of the high radar-reflectivity region corresponding to active convections in NoTS-NoSE was slightly smaller than that in TSNoSE. It indicates that the convections in NoTS-NoSE are not well-organized, compared with that in TS-NoSE. The evolution of the BL flow in NoTS-NoSE is similar to that in TS-NoSE (Figs. 13a, b). Consistent with the BL evolution, horizontal water vapor flux convergence over the Taipei basin exhibited similar evolution between NoTS-NoSE and TS-NoSE (Fig. 14a).

Coincided with the development of the afternoon TSs, the rainfall amount for TS-NoSE was enhanced from 1200 LST over the Taipei basin (Fig. 14b). Although the rainfall amount in NoTS-NoSE was also enhanced around the afternoon, the starting time was about 1-h delayed than that in TS-NoSE (Fig. 14b). The water vapor fluxes supplied into the Taipei basin associated with the sea-breeze circulation are consumed to moisten the dry middle troposphere at the initial time in the NoTS-NoSE experiment. The delayed precipitation due to the moistening in the NoTS-NoSE 
(a) NOTS-NOSE

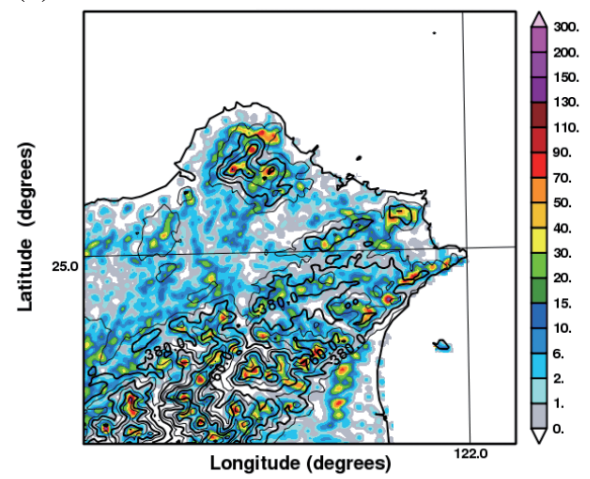

(c) NOTS-SE

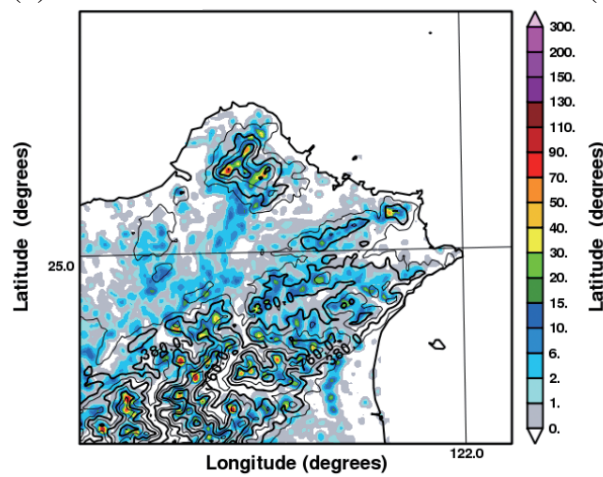

(b) TS-NOSE

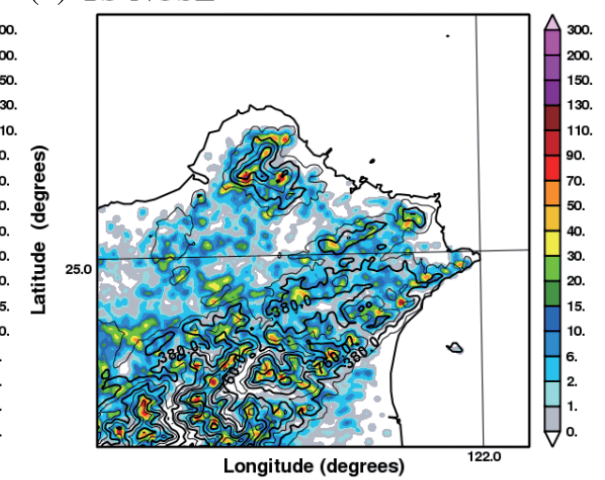

(d) TS-SE

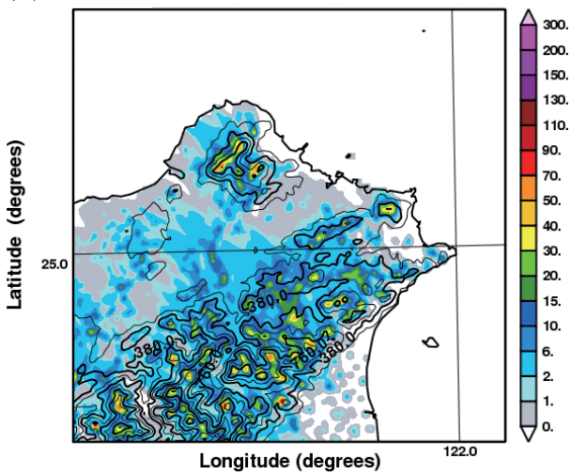

Fig. 11. Accumulated rainfall (shading, mm) during 0500 LST to 1800 LST and terrain height (contour, m) for the four ideal simulations. The left and right panels are based on dry NOTS sounding (26 June) and moist TS sounding (30 June), while the top and bottom panels correspond to no environmental flow and southeasterly environmental flow.

(a) NOTS-NOSE

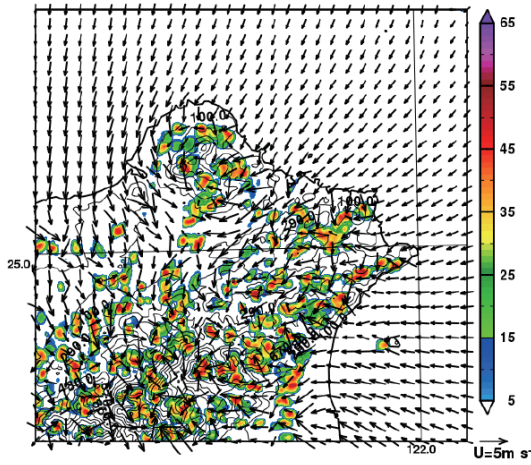

(c) NOTS-SE

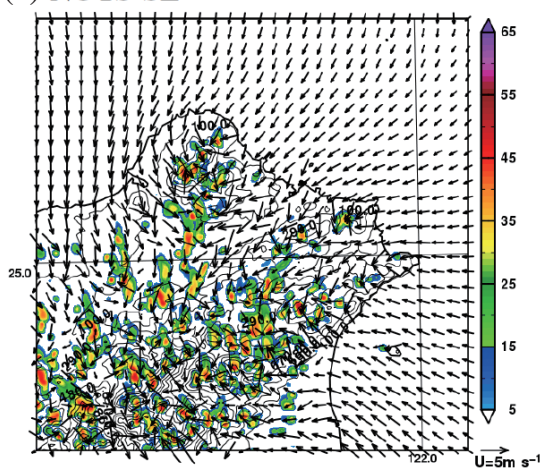

(b) TS-NOSE

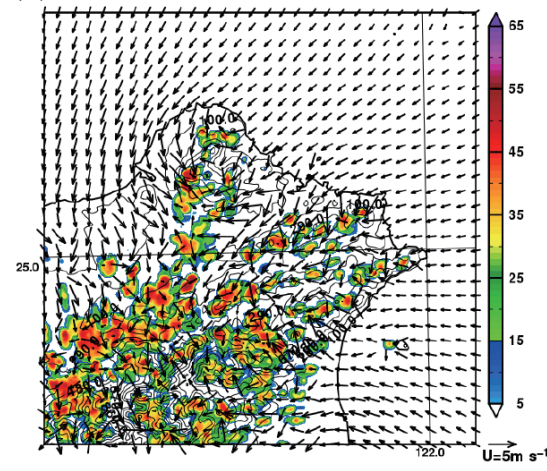

(d) TS-SE

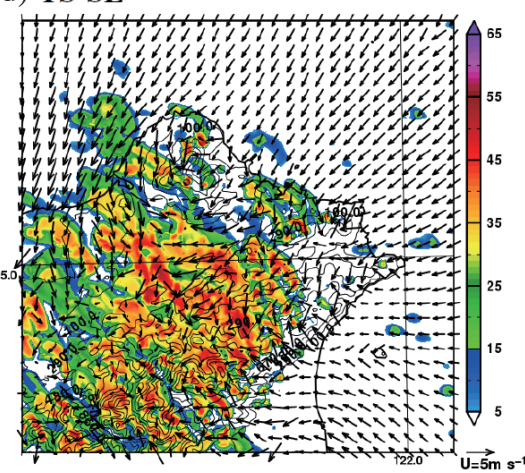

Fig. 12. As in Fig. 11, except for the maximum radar reflectivity (shading, dBZ), terrain height (contour, m), and 10-m horizontal winds (vector) at $1400 \mathrm{LST}$. 

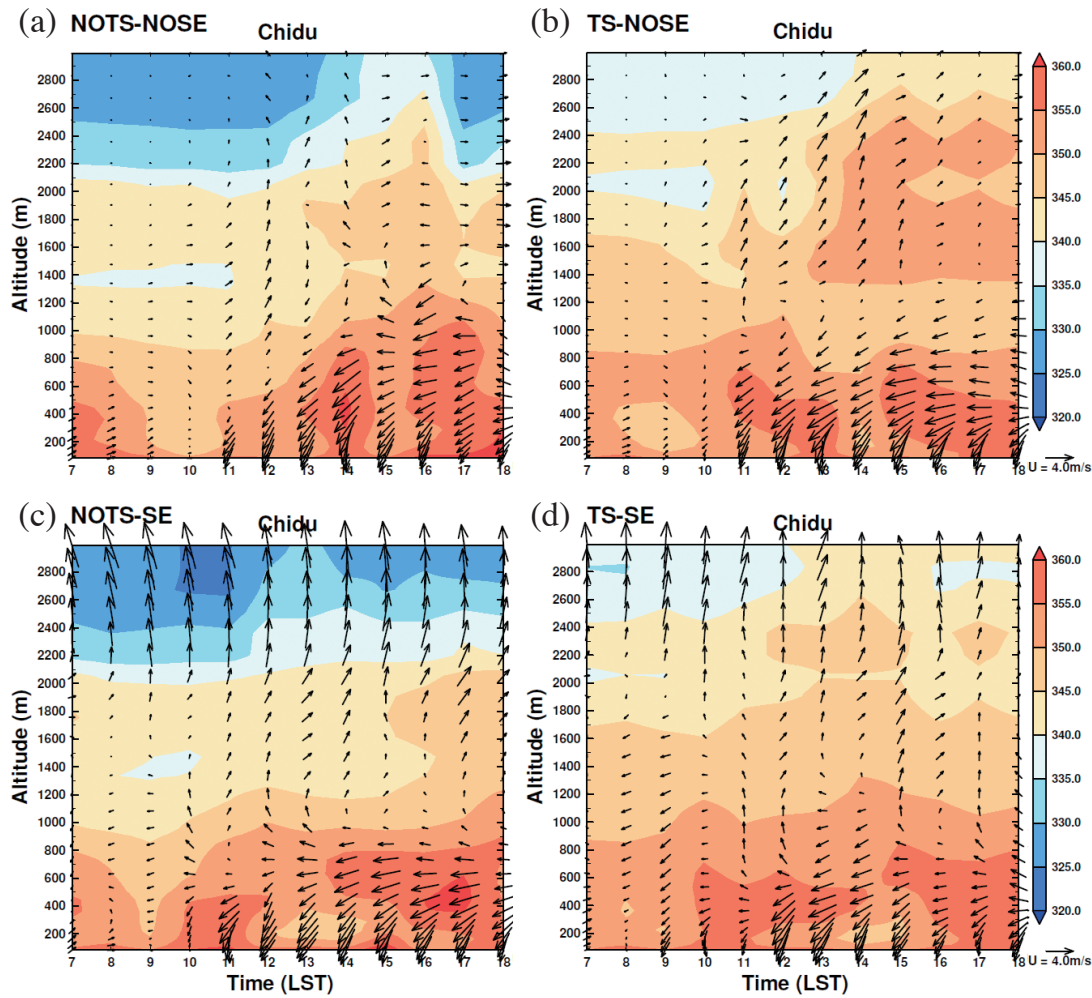

Fig. 13. Time-height cross-sections of horizontal winds and $\theta_{e}$ (shading; K) at Chidu for the idealized experiments. The left and right panels are based on dry NOTS sounding (26 June) and moist TS sounding (30 June), while the top and bottom panels correspond to no environmental flow and southeasterly environmental flow.

(a) Qv flux @ $10 \mathrm{~m}\left(\times 10^{-6} \mathrm{~kg} \mathrm{~m}^{-4} \mathrm{~s}^{-1}\right)$

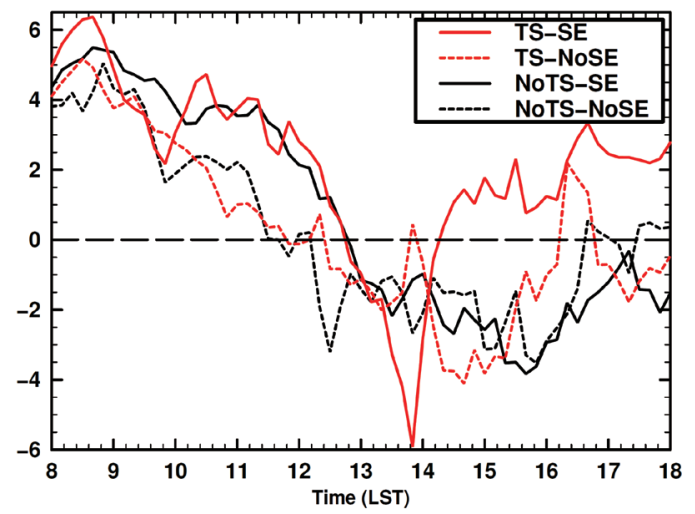

(b) Areal mean rainfall every $10 \mathrm{~min}(\mathrm{~mm})$

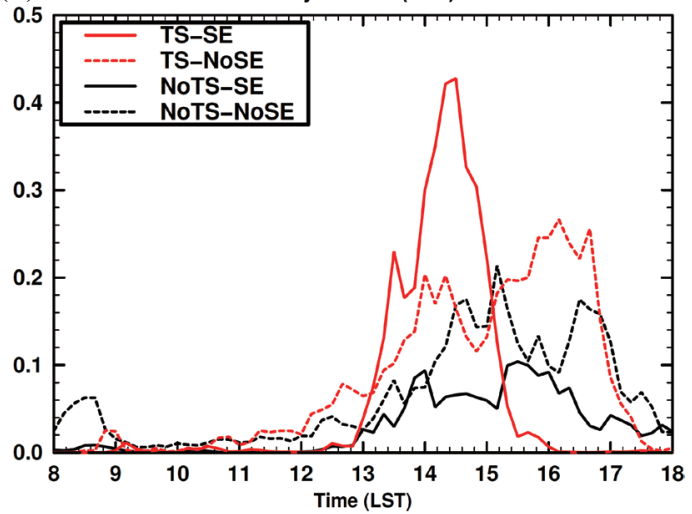

Fig. 14. Time series of the areal average of (a) horizontal water vapor flux divergence at the 10-m height and (b) rainfall over the area indicated by the blue rectangle in Fig. $3 \mathrm{~b}$. 
experiment is similar to cases of precipitation events in eastern China (Shinoda and Uyeda 2002). During the moistening process, the convections transported airmass with high $\theta_{e}$ to dry layer with low $\theta_{e}$ as shown around the horizontal distances of $15 \mathrm{~km}$ in Fig. $15 \mathrm{~b}$ and $22 \mathrm{~km}$ in Fig. 15c. Until the middle-level air is saturated, deep convective clouds are difficult to develop over the basin. Note that the area over the Taipei basin is relatively smaller than that of eastern China studied in Shinoda and Uyeda (2002). Thus, the period required to moisten the middle-level can be only $1-\mathrm{h}$ in the present case. We conclude that the moisture profile in the middle troposphere is not the only factor for organizing the afternoon TSs over the Taipei basin.

\subsection{Role of Middle-Level Environmental Flow}

The NoTS-SE experiment was compared with the NoTS-NoSE experiment to examine the role of prevailing middle-level southeasterly flow that appeared in the real NoTS simulation. Accumulated rainfall in NoTS-SE was considerably reduced (Figs. 11a, c). The peak value of the areal-averaged rainfall over the basin is half of NoTS-NoSE (Fig. 14b). However, the sea breeze near the surface in the afternoon is not essentially different between NoTS-NoSE and NoTS-SE (Figs. 12a, c), while the depth of the seabreeze circulation was slightly suppressed below a height of 1000 m (Figs. 13a, c).

Of interest is the similarity in the maxima of watervapor-flux convergence in the afternoon between the simulations with and without the prevailing flow associated with the NoTS initial sounding, despite quite the difference in the afternoon rainfall amount between these two cases (Figs. 14a, b). The low-level onshore flow can mainly induce water-vapor-flux convergence. Thus, the difference in rainfall amount might be due to the relatively shallow $\mathrm{BL}$ depth in NoTS-SE (Figs. 13a, c). However, the flux convergence associated with the onshore flow still dominated the layer under $600 \mathrm{~m}$ for both cases.

Another reason explaining the reduced rainfall in NoTS-SE is the "ventilation" effect due to the prevailing middle-level flow. In the case of apparent prevailing wind associated with the middle-level dry layer, the middle-level air mass moistened by shallow convections over the Taipei basin is continuously transported downstream by the prevailing flow. Subsequently, the dry air mass is transported from the upstream into the Taipei basin. Despite the similar afternoon maxima of the water-vapor-flux convergence between NoTS-NoSE and NoTS-SE, the middle-level ventilation can reduce the rainfall peak and accumulated amount over the basin. In the afternoon of NoTS-SE, dry airmass with low $\theta_{e}$ in heights of 3 to $5 \mathrm{~km}$ is transported from the upstream (i.e., the side of B in Figs. 15d - f) to the downstream (i.e., the side of $\mathrm{B}^{\prime}$ in Figs. 15d - f). In contrast to the NoTS-NoSE, dry air mass $\left(\theta_{e}<330 \mathrm{~K}\right)$ is maintained in the middle level over the Taipei basin at 1700 LST (Figs. 15c, f).

Finally, we examined the ventilation effect due to the prevailing flow depending on the moisture profile (i.e., TS versus NoTS). The TS-SE experiment is performed as the same prevailing flow in NoTS-SE. Although the evolution of dynamic and thermodynamic structures within the BL in TS-SE is similar to that in NoTS-SE (Figs. 13c, d) ${ }^{4}$, the area with high radar reflectivity was extensive in the afternoon (Fig. 12d). The TS-SE experiment doubled the peak amount of the areal averaged rainfall over the basin in TS-NoSE (Fig. 14b). In this case, deep convections affected by insufficient entrainment develop over the Taipei basin because of middle-level moist air mass associated with the prevailing flow. In addition, the prevailing flow can transport water condensates associated with well-developed convective clouds. Note that the convective clouds developed around mountains are located on the southern side of the Taipei basin. Thus, the water condensates transported by the southeasterly wind can precipitate downstream (i.e., on the Taipei basin). The transport of the water condensates is revealed by the distributions of radar reflectivity tilted downstream (i.e., from the side of B to B' in Fig. 15k). The transport due to the prevailing wind can increase rainfall over the Taipei basin and generate secondary convective clouds around the basin due to widespread cold pool associated with the precipitation as previously proposed (e.g., Jou et al. 2016; Miao and Yang 2020).

In addition to the vertical thermodynamic profile, the prevailing middle-level flow also affects the TS organization over the Taipei basin. In a drier profile, the prevailing wind acts to suppress the organization of the deep convections. In a much moist profile, the prevailing wind acts to help the development of the convections and causes heavy precipitation. Note that the idealized simulation in NoTSSE could not reproduce less rainfall than that of the real NoTS simulation. It is thus suggested that the essential factors in the NoTS case are not only middle-level moisture and horizontal wind fields. A possible factor is synopticscale subsidence associated with the subtropical high. However, it is too difficult to examine the role of subsidence in the present idealized framework.

\section{CONCLUSIVE REMARKS}

In the Taipei metropolitan area, afternoon TSs over the basin in Mei-yu and summer seasons often cause meteorological hazards. The TSs can be caused by locally diurnal

4 In Figs. 13c, d, there is southerly wind near $3 \mathrm{~km}$. The prevailing southeasterly wind was given above the 2-km height in NoTS-SE and TS-SE. Without the prevailing wind, the dominant wind above the 2-km is southwesterly associated with the sea-breeze circulation. Thus, if the prevailing wind is superposed on the sea-breeze circulation, the dominant wind direction is close to southerly wind. 
(a) 11 LST NoTS-NoSE

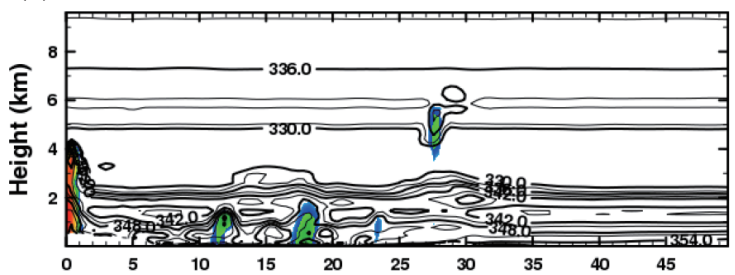

(b) 14 LST

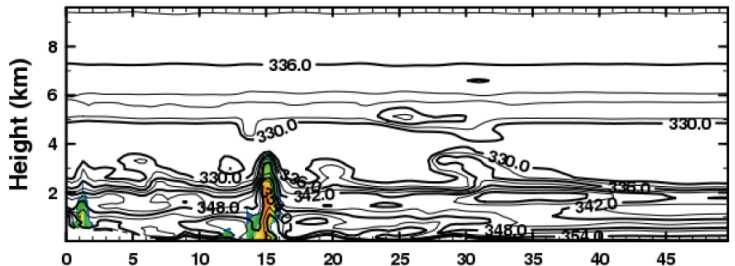

(c) $17 \mathrm{LST}$

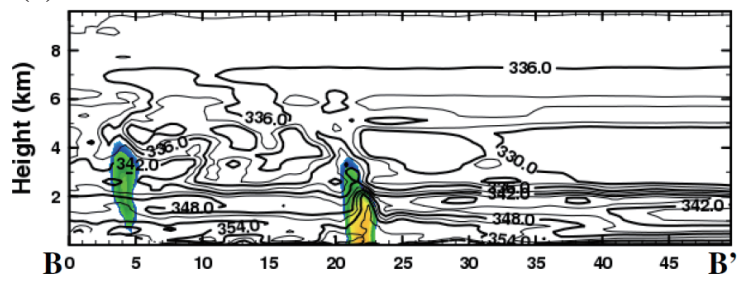

(d) $11 \mathrm{LST}$

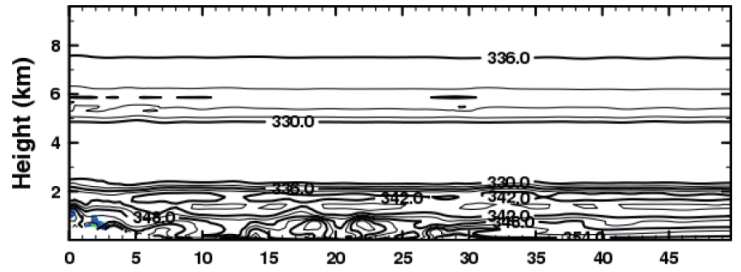

(e) 14 LST

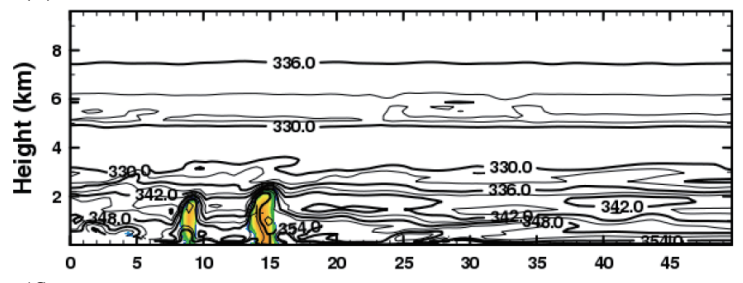

(f) $17 \mathrm{LST}$

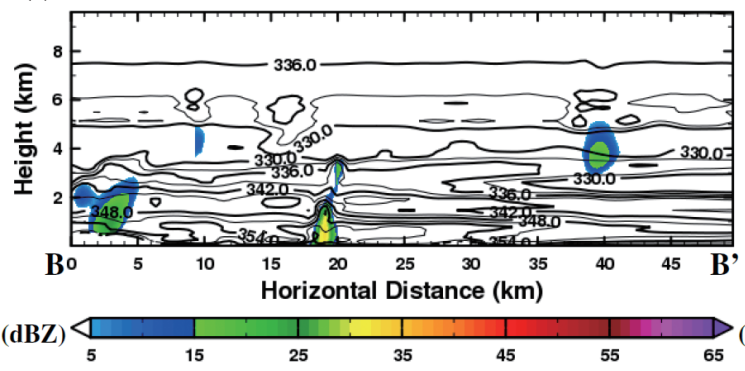

(g) 11 LST TS-NoSE

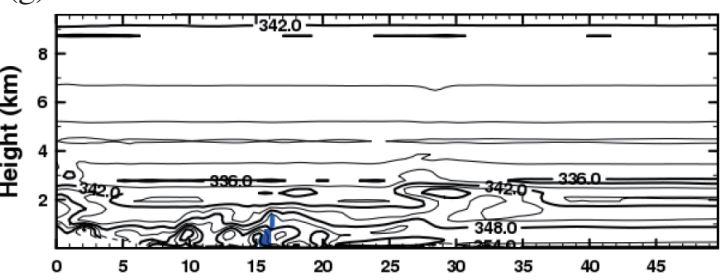

(h) 14 LST

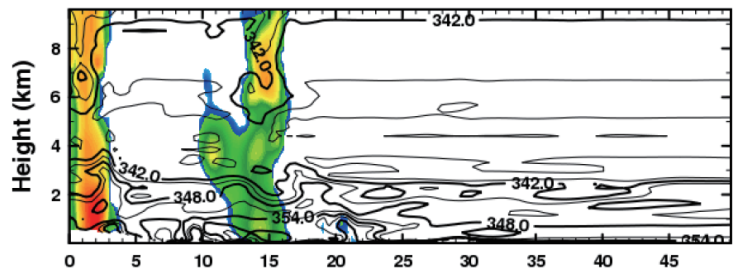

(i) $17 \mathrm{LST}$

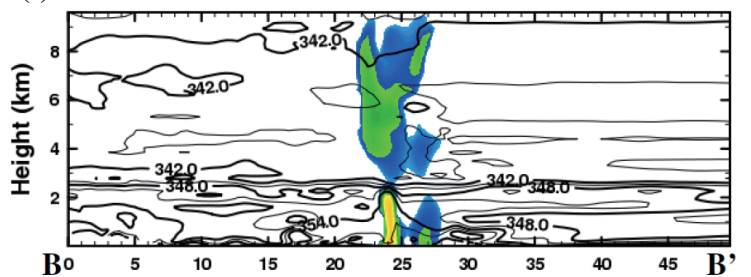

(j) 11 LST TS-SE

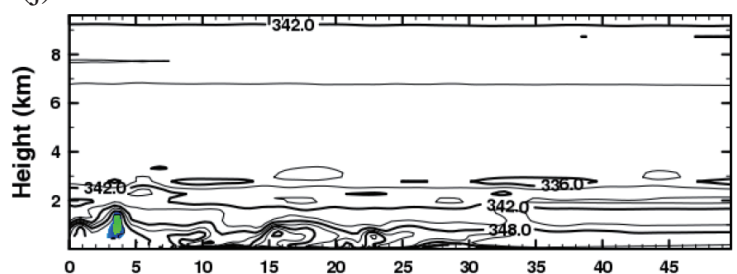

(k) 14 LST

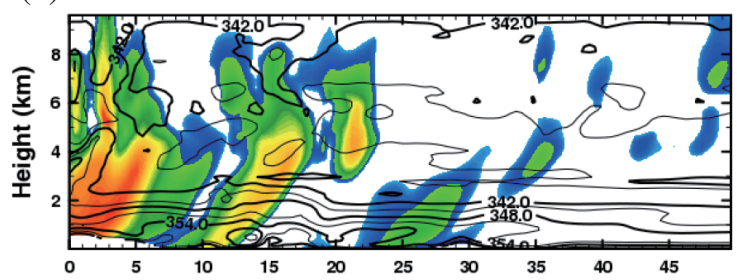

(1) 17 LST

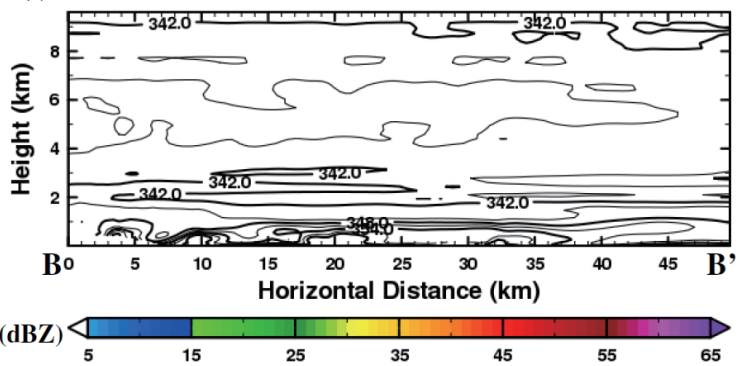

Fig. 15. As in Fig. 9, except for only the B-B' section for (a) - (c) NoTS-NoSE, (d) - (f) NoTS-SE, (g) - (i) TS-NoSE, and (j) - (1) TS-SE experiments. 
circulation (i.e., land-sea breezes) under weak synopticscale disturbances. Understanding essential factors of TS organization is important for improving numerical prediction. Previous studies have proposed multiple possible factors, including low-level water vapor, urbanization and surface conditions over the basin, dynamic and thermodynamic fields in the environment, and topography. A straightforward way to tackle this problem is by comparing the factors between TS and no-TS cases. Recently, a field campaign during June to August in 2018 observed temporally detailed evolution of BL associated with the sea-breeze circulation over the Taipei basin in the daytime using a new instrument (i.e., Storm Tracker) and environmental dynamic and thermodynamic structure by additional upper soundings.

This study investigates the roles of environmental dynamic and thermodynamic fields on the organization of the afternoon TSs over the Taipei basin. A non-hydrostatic model with a sub-km resolution in horizontal was used to simulate a real TS event under weak synoptic disturbances around Taiwan on 30 June 2018 and a no-TS event on 26 June 2018. Accumulated rainfall amount in the simulations was compared with CWB rain gauges. Reasonable results on both cases were verified by hourly observation of the BL structure and operational upper-level soundings around the Taipei basin in the TASSE campaign.

Although the clear sea-breeze circulations occurred in the BL for both cases under weak synoptic influences, several differences in environmental fields were found. For the TS case, a moist environment with weak prevailing flows was observed through the whole troposphere. In contrast, a dry layer with clear southeasterly flows associated with the subtropical high covered above the 2-km height for the NoTS case. This difference was also captured in the simulations.

As suggested by Shinoda and Uyeda (2002) in a case study of the eastern China TS, the middle-level moisture can play a key role in the development of deep convective clouds due to reducing buoyancy in the clouds through entrainment. The feature was also found in the Taipei basin by Lin et al. (2011b). Moreover, the prevailing wind in the middle troposphere can play an additional role in developing the clouds by keeping the entrainment due to the continuous supply of dry airmass (referred to as the "ventilation" effect) newly proposed by the present study.

Additional experiments in more idealized settings were conducted to isolate the roles of these factors on the TS organization. The role of the middle-level moisture was examined by idealized simulations (NoTS-NoSE and TSNoSE) with different soundings from the NoTS and TS cases without any prevailing flows. Despite the difference in the middle-level moisture, the accumulated rainfall and BL evolution for the two experiments resemble each other. Note that the start time of the afternoon rainfall for NoTSNoSE was 1-h later than that for TS-NoSE. Consistent with Shinoda and Uyeda (2002), the delay indicates that shallow convections gradually moistened the dry layer in the middle level over the Taipei basin during the morning and early afternoon. However, the time required for moistening in this case study was relatively shorter than the case studied by Shinoda and Uyeda (2002) because of the small area around the Taipei basin.

The role of the prevailing flows in the middle troposphere was examined by another idealized simulation (NoTS-SE) with an upper sounding in the NoTS case and prevailing flows given by an analytical function. The peak rainfall is half of that in the NoTS-NoSE. This reduced rainfall indicates that the development of deep convections was suppressed by continuous supply (i.e., ventilation) of dry air mass associated with the prevailing middle-level southeasterly flows. Note that the ventilation effect due to the prevailing flow highly depends on the moisture profile in the same layer as the prevailing flows. When the prevailing flow layer has high humidity, the ventilation is difficult to suppress the deep convections because the reduced buoyancy is insufficient to constrain the upward motion.

In summary, both the middle-level moisture and prevailing wind profiles in the environment are critical for TS organization over the Taipei basin. In particular, the present study newly found the importance of the prevailing flows in addition to the importance of the middle-level moisture by Lin et al. (2011b). The present study suggests that observations of the wind and thermal profiles in the upstream side of the Taipei basin are vital for more accurate forecasts of the afternoon TSs over the Taipei basin. As the present study focuses on limited rainfall cases, statistical studies based on simulations of many cases and idealized simulations are recommended in the future. Moreover, we focused on the prevailing wind and moisture in the middle troposphere under a typical situation without any synoptic disturbances around Taiwan in this study. However, the prevailing wind is sometimes dominated by low-level northeasterly and middle-level southwesterly winds when typhoons approach in Taiwan. They can be a favorable environment of vertical wind shear for the afternoon TS development, which is suggested to be examined in the future.

Acknowledgements The Storm-Tracker data are operated and provided by the TASSE project. The numerical simulations in this work were performed on the FX100 and FX1000 supercomputer systems at the Information Technology Center, supported by the computational joint research program of the Institute for Space-Earth Environmental Research (ISEE), Nagoya University. ST thanks Dr. Mayumi K. Yoshioka in National Institute of Information and Communications Technology and Mr. Koichi Hasegawa in Chuden CTI Co., Ltd. for the porting of the RRTM-G package to the CReSS model. The verification of the simulation used the radar and sounding data in the Banqiao observatory operated and provided by the CWB. Figures were produced by a 
drawing library of Dennou Common Library developed and maintained by GFD-Dennou-Club (http://www.gfd-dennou. org/library/dcl/). This work was funded by Grant 110-2123M-002-007- and 110-2111-M-002-016- of the Ministry of Science and Technology, Taiwan.

\section{REFERENCES}

Chen,C.-S.,W .-S.Chen, andZ.Deng, 1991: Astudy of amountain-generated precipitation system in northern Taiwan during TAMEX IOP 8. Mon. Weather Rev., 119, 25742607, doi: 10.1175/1520-0493(1991)119<2574:ASOA $\mathrm{MG}>2.0 . \mathrm{CO} ; 2$. [Link $]$

Chen, C.-S., C.-L. Liu, M.-C. Yen, C.-Y. Chen, P.-L. Lin, C.-Y. Huang, and J.-H. Teng, 2010: Terrain effects on an afternoon heavy rainfall event, observed over northern Taiwan on 20 June 2000 during Monsoon break. J. Meteorol. Soc. Jpn., 88, 649-671, doi: 10.2151/ jmsj.2010-403. [Link]

Chen, T.-C., S.-Y. Wang, and M.-C. Yen, 2007: Enhancement of afternoon thunderstorm activity by urbanization in a valley: Taipei. J. Appl. Meteorol. Climatol., 46, 1324-1340, doi: 10.1175/JAM2526.1. [Link]

Chen, T.-C., M.-C. Yen, J.-D. Tsay, C.-C. Liao, and E. S. Takle, 2014: Impact of afternoon thunderstorms on the land-sea breeze in the Taipei basin during summer: An experiment. J. Appl. Meteorol. Climatol., 53, 17141738, doi: 10.1175/JAMC-D-13-098.1. [Link]

Deardorff, J. W., 1980: Stratocumulus-capped mixed layers derived from a three-dimensional model. Bound.-Layer Meteor., 18, 495-527, doi: 10.1007/BF00119502. [Link]

Hwang, W.-C., P.-H. Lin, and H. Yu, 2020: The development of the "Storm Tracker" and its applications for atmospheric high-resolution upper-air observations. Atmos. Meas. Tech., 13, 5395-5406, doi: 10.5194/amt13-5395-2020. [Link]

Iacono, M. J., J. S. Delamere, E. J. Mlawer, and S. A. Clough, 2003: Evaluation of upper tropospheric water vapor in the NCAR Community Climate Model (CCM3) using modeled and observed HIRS radiances. J. Geophys. Res., 108, ACL 1-1-ACL1 -19, doi: 10.1029/2002JD002539. [Link]

Johnson, R. H. and J. F. Bresch, 1991: Diagnosed characteristics of precipitation systems over Taiwan during the May-June 1987TAMEX.Mon.WeatherRev.,119,25402557, doi: 10.1175/1520-0493(1991)119<2540:DCOP$\mathrm{SO}>2.0 . \mathrm{CO} ; 2$. [Link]

Jou, B. J.-D., Y.-C. Kao, R.-G. R. Hsiu, C.-J. U. Jung, J. R. Lee, and H. C. Kuo, 2016: Observational characteristics and forecast challenge of Taipei flash flood afternoon thunderstorm: Case study of 14 June 2015. Atmos. Sci., 44, 57-82. (in Chinese with English abstract) Klemp, J. B. and R. B. Wilhelmson, 1978: The simula- tion of three-dimensional convective storm dynamics. J. Atmos. Sci., 35, 1070-1096, doi: 10.1175/15200469(1978)035<1070:TSOTDC>2.0.CO;2. [Link]

Kondo, J., 1975: Air-sea bulk transfer coefficients in diabatic conditions. Bound.-Layer Meteor., 9, 91-112, doi: 10.1007/BF00232256. [Link]

Kuo, K.-T. and C.-M. Wu, 2019: The precipitation hotspots of afternoon thunderstorms over the Taipei basin: Idealized numerical simulations. J. Meteorol. Soc. Jpn., 97, 501-517, doi: 10.2151/jmsj.2019-031. [Link]

Lin, C.-Y., W.-C. Chen, P.-L. Chang, and Y.-F. Sheng, 2011a: Impact of the urban heat island effect on precipitation over a complex geographic environment in northern Taiwan. J. Appl. Meteorol. Climatol., 50, 339-353, doi: 10.1175/2010JAMC2504.1. [Link]

Lin, P.-F., P.-L. Chang, B. J.-D. Jou, J. W. Wilson, and R. D. Roberts, 2011b: Warm season afternoon thunderstorm characteristics under weak synoptic-scale forcing over Taiwan island. Weather Forecast., 26, 44-60, doi: 10.1175/2010WAF2222386.1. [Link]

Lin, Y.-L., 2007: Mesoscale Dynamics, Cambridge University Press, Cambridge, 630 pp, doi: 10.1017/ CBO9780511619649. [Link]

Louis, J. F., M. Tiedtke, and J. F. Geleyn, 1982: A short history of the operational PBL - parameterization at ECMWF. Proc. ECMWF Workshop on Planetary Boundary Layer Parameterization, Reading, United Kingdom, ECMWF, 59-79.

Miao, J.-E. and M.-J. Yang, 2020: A modeling study of the severe afternoon thunderstorm event at Taipei on 14 June 2015: The roles of sea breeze, microphysics, and terrain. J. Meteorol. Soc. Jpn., 98, 129-152, doi: 10.2151/jmsj.2020-008. [Link]

Miller, S. T. K., B. D. Keim, R. W. Talbot, and H. Mao, 2003: Sea breeze: Structure, forecasting, and impacts. Rev. Geophys., 41, doi: 10.1029/2003RG000124. [Link]

Miyamoto, Y., Y. Kajikawa, R. Yoshida, T. Yamaura, H. Yashiro, and H. Tomita, 2013: Deep moist atmospheric convection in a subkilometer global simulation. Geophys. Res. Lett., 40, 4922-4926, doi: 10.1002/ grl.50944. [Link]

Mlawer, E. J., S. J. Taubman, P. D. Brown, M. J. Iacono, and S. A. Clough, 1997: Radiative transfer for inhomogeneous atmospheres: RRTM, a validated correlated-k model for the longwave. J. Geophys. Res., 102, 1666316682, doi: 10.1029/97JD00237. [Link]

Murakami, M., 1990: Numerical modeling of dynamical and microphysical evolution of an isolated convective cloud: The 19 July 1981 CCOPE cloud. J. Meteorol. Soc. Jpn., 68, 107-128, doi: 10.2151/ jmsj1965.68.2_107. [Link]

Murakami, M., T. L. Clark, and W. D. Hall, 1994: Numerical simulations of convective snow clouds over the Sea of Japan: Two-dimensional simulations of mixed 
layer development and convective snow cloud formation. J. Meteorol. Soc. Jpn., 72, 43-62, doi: 10.2151/ jmsj1965.72.1_43. [Link]

Sano, T. and K. Tsuboki, 2006: Structure and evolution of a cumulonimbus cloud developed over a mountain slope with the arrival of sea breeze in summer. J. Meteorol. Soc. Jpn., 84, 613-640, doi: 10.2151/jmsj.84.613. [Link]

Segami, A., K. Kurihara, H. Nakamura, M. Ueno, I. Takano, and Y. Tatsumi, 1989: Operational mesoscale weather prediction with Japan Spectral Model. J.Meteorol.Soc. Jpn., 67, 907-924, doi: 10.2151/jmsj1965.67.5_907. [Link]

Shinoda, T. and H. Uyeda, 2002: Effective factors in the development of deep convective clouds over the wet region of Eastern China during the summer monsoon season. J. Meteorol. Soc. Jpn., 80, 1395-1414, doi: 10.2151/jmsj.80.1395. [Link]

Tsuboki, K. and A. Sakakibara, 2002: Large-scale parallel computing of Cloud Resolving Storm Simulator. In: Zima, H. P., K. Joe, M. Sato, Y. Seo, and M. Shimasaki (Eds.), High Performance Computing: 4th International Symposium, ISHPC 2002 Kansai Science City, Japan, May 15-17, 2002 Proceedings, Lecture Notes in Computer Science, Vol. 2327, Springer, Berlin, Heidelberg, 243-259, doi: 10.1007/3-540-47847-7_21. [Link]

Tsujino, S., K. Tsuboki, and H.-C. Kuo, 2017: Structure and maintenance mechanism of long-lived concentric eyewalls associated with simulated Typhoon Bolaven (2012). J. Atmos. Sci., 74, 3609-3634, doi: 10.1175/ JAS-D-16-0236.1. [Link]

Wang, C.-C., J. C.-S. Hsu, G. T.-J. Chen, and D.-I. Lee, 2014a: A study of two propagating heavy-rainfall episodes near Taiwan during SoWMEX/TiMREX IOP-8 in June 2008. Part I: Synoptic evolution, episode propagation, and model control simulation. Mon. Weather Rev., 142, 2619-2643, doi: 10.1175/MWRD-13-00331.1. [Link]

Wang, C.-C., J. C.-S. Hsu, G. T.-J. Chen, and D.-I. Lee, 2014b: A study of two propagating heavy-rainfall episodes near Taiwan during SoWMEX/TiMREX IOP8 in June 2008. Part II: Sensitivity tests on the roles of synoptic conditions and topographic effects. Mon. Weather Rev., 142, 2644-2664, doi: 10.1175/MWRD-13-00330.1. [Link]

Wang, C.-C., B.-K. Chiou, G. T.-J. Chen, H.-C. Kuo, and C.-H. Liu, 2016: A numerical study of back-building process in a quasistationary rainband with extreme rainfall over northern Taiwan during 11-12 June 2012. Atmos. Chem. Phys., 16, 12359-12382, doi: 10.5194/ acp-16-12359-2016. [Link]

Wang, C.-C., G. T.-J. Chen, C.-H. Ngai, and K. Tsuboki, 2018: Case study of a morning convective rainfall event over southwestern Taiwan in the Mei-yu season under weak synoptic conditions. J. Meteorol. Soc. Jpn., 96, 461-484, doi: 10.2151/jmsj.2018-051. [Link] Yamada, H., 2008: Numerical simulations of the role of land surface conditions in the evolution and structure of summertime thunderstorms over a flat highland. Mon. Weather Rev., 136, 173-188, doi: 10.1175/2007MWR2053.1. [Link]

Yamada, H., B. Geng, H. Uyeda, and K. Tsuboki, 2007a: Thermodynamic impact of the heated landmass on the nocturnal evolution of a cloud cluster over a MeiyuBaiu front. J. Meteorol. Soc. Jpn., 85, 663-685, doi: 10.2151/jmsj.85.663. [Link]

Yamada, H., B. Geng, H. Uyeda, and K. Tsuboki, 2007b: Role of the heated landmass on the evolution and duration of a heavy rain episode over a Meiyu-Baiu frontal zone. J. Meteorol. Soc. Jpn., 85, 687-709, doi: 10.2151/jmsj.85.687. [Link]

\section{APPENDIX A. HELICITY FOR THE STEADY STATE OF UNIFORM FLOWS ON A ROTATING SYSTEM}

In the appendix, we mathematically prove that any horizontal flows in a steady state on a rotating system have no helicity. Let consider a horizontally uniform and steadystate flow $\boldsymbol{U}=\boldsymbol{U}(z)$ with vertical wind shear on the Cartesian coordinates $(x, y, z)$. We assume that vertical component of the flow vanishes without any external forcing. Then, the governing equations in the CReSS model are

$\nabla p^{\prime}=-\bar{\rho} f \boldsymbol{k} \times \boldsymbol{U}$

$\frac{\partial p^{\prime}}{\partial z}=-g(\rho-\bar{\rho})$

$0=\boldsymbol{U} \cdot \nabla p^{\prime}$

$0=\boldsymbol{U} \cdot \nabla \theta^{\prime}$

where $\boldsymbol{k}$ is the vertical unit vector. Symbols of $p^{\prime}, \theta^{\prime}$, and $\bar{\rho}$ are perturbations of pressure and potential temperature from horizontal average, and horizontal average of air density, respectively. $\nabla$ is the horizontal gradient operator. $g$ and $f$ are gravitational acceleration and the Coriolis parameter (constant), respectively. Then, we consider that water vapor is horizontally uniform. Equation (A1) is the geostrophic balance. In taking $\partial(\mathrm{A} 1) / \partial z-\nabla(\mathrm{A} 2)$, we obtain the thermal wind relationship:

$\nabla \rho=\frac{f}{g} \boldsymbol{k} \times \frac{\partial \bar{\rho} \boldsymbol{U}}{\partial z}$ 
Moreover, $\theta$ for dry air is represented as the following:

$\theta=\frac{p}{R_{d} \rho}\left(\frac{p}{p_{00}}\right)^{-R_{d} / C_{p}}$

$R_{d}, C_{p}$, and $p_{00}$ are the gas constant for dry air, specific heat for dry air, and a reference pressure of $1000 \mathrm{hPa}$, respectively. In calculating $\boldsymbol{U} \cdot \nabla(\mathrm{A} 6)$, we obtain

$\boldsymbol{U} \cdot \nabla \theta=\frac{\boldsymbol{U}}{\rho} \cdot \nabla \rho+\left(1-\frac{R_{d}}{C_{p}}\right) \frac{\boldsymbol{U}}{p} \cdot \nabla p$

The above is rearranged using relationships of Eqs. (A3) and (A4):

$0=\boldsymbol{U} \cdot \nabla \rho$

Equations (A3), (A4), and (A8) imply that the flow $\boldsymbol{U}$ on the steady state streams along isolines of thermodynamic fields (i.e., potential temperature, pressure and air density).

On the other hand, the flow is also constrained by the thermal wind relationship Eq. (A5). In calculating $\boldsymbol{U} \cdot(\mathrm{A} 5)$, we obtain a constraint:

$\boldsymbol{U} \cdot \nabla \rho=\frac{f}{g} \boldsymbol{U} \cdot \boldsymbol{k} \times \frac{\partial \bar{\rho} \boldsymbol{U}}{\partial z}$

The steady-state flow $\boldsymbol{U}$ must satisfy the two constraints of
Eqs. (A8) and (A9). Thus,

$\boldsymbol{U} \cdot \boldsymbol{k} \times \frac{\partial \bar{\rho} \boldsymbol{U}}{\partial z}=0$

Then, we define the unit vector of $\boldsymbol{U}$ as $\boldsymbol{i} \equiv \boldsymbol{U} /|\boldsymbol{U}|$. Equation (A10) is

$|\boldsymbol{U}| \boldsymbol{i} \cdot \boldsymbol{k} \times \frac{\partial \bar{\rho}|\boldsymbol{U}| \boldsymbol{i}}{\partial z}=0$

On the basis of a vector identity of $\boldsymbol{i} \cdot \boldsymbol{k} \times \boldsymbol{i}=0$, Eq. (A11) is rearranged as:

$\boldsymbol{i} \cdot \boldsymbol{k} \times \frac{\partial \boldsymbol{i}}{\partial z}=0$

This implies $\partial \boldsymbol{i} / \partial z=\mathbf{0}$, which is no helicity. Therefore, it is proved that the steady-state flow with any vertical wind shear on the rotating system has no helicity. On the other hand, $\partial|\boldsymbol{U}| / \partial z$ is not required to vanish. This indicates that any vertical wind shears are allowed in the steady-state flow.

We caution that the constraint for the helicity is a unique feature on the "rotating" system. In actual, the righthand side of Eq. (A9) always vanishes on any non-rotating systems (i.e., $f=0$ ), regardless of any helicities. Thus, we can consider the steady-state flows with any helicities on the non-rotating systems. 